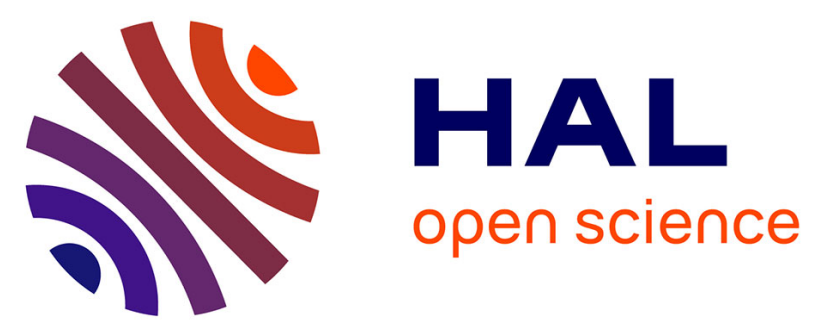

\title{
Formation and characterization of hydride blisters in Zircaloy 4 cladding tubes
}

Arthur Hellouin de Menibus, Quentin Auzoux, Ousmane Dieye, Pascal Berger, Sophie Bosonnet, Eddy Foy, Vincent Macdonald, Jacques Besson, Jérôme Crépin

\section{To cite this version:}

Arthur Hellouin de Menibus, Quentin Auzoux, Ousmane Dieye, Pascal Berger, Sophie Bosonnet, et al.. Formation and characterization of hydride blisters in Zircaloy 4 cladding tubes. Journal of Nuclear Materials, 2014, 449, pp.132-147. 10.1016/j.jnucmat.2014.03.006 . hal-00980723

\section{HAL Id: hal-00980723}

https://hal-mines-paristech.archives-ouvertes.fr/hal-00980723

Submitted on 18 Apr 2014

HAL is a multi-disciplinary open access archive for the deposit and dissemination of scientific research documents, whether they are published or not. The documents may come from teaching and research institutions in France or abroad, or from public or private research centers.
L'archive ouverte pluridisciplinaire HAL, est destinée au dépôt et à la diffusion de documents scientifiques de niveau recherche, publiés ou non, émanant des établissements d'enseignement et de recherche français ou étrangers, des laboratoires publics ou privés. 


\title{
Formation and Characterization of Hydride Blisters in Zircaloy-4 Cladding Tubes
}

Arthur Hellouin de Menibus*1,3, Quentin Auzoux², Ousmane Dieye $^{2}$, Pascal Berger ${ }^{4,5}$, Sophie Bosonnet ${ }^{1}$, Eddy Foy ${ }^{4,5}$, Vincent Macdonald ${ }^{2}$, Jacques Besson ${ }^{3}$, and Jerome Crépin ${ }^{3}$

${ }^{1}$ CEA Saclay/DEN/DANS/DMN/SRMA, 91191 Gif-sur-Yvette, France ${ }^{2}$ CEA Saclay/DEN/DANS/DMN/SEMI, 91191 Gif-sur-Yvette, France

${ }^{3}$ Mines ParisTech/Centre des materiaux CNRS UMR 7633, 91003 Evry, France

${ }^{4}$ CEA Saclay/DSM/IRAMIS/SIS2M, 91191 Gif-sur-Yvette, France

${ }^{5}$ CNRS UMR 3299, CEA-Saclay, 91191 Gif sur Yvette

Published in 2014 in The Journal of Nuclear Materials: http://www.sciencedirect.com/science/article/pii/S0022311514001135

\begin{abstract}
This article is focused on the formation of hydride blisters in zirconium alloys an experimental and theoritical standpoint, and their characterization in terms of morphology, hydrides crystallographic phases, hardness and hydrogen concentration. An experimental setup was developed to grow hydride blisters on pre-hydrided Zircaloy-4 cladding tubes by thermo-diffusion. The thermal conditions were optimized based on thermo-diffusion calculations, that take into account the hysteresis in the hydrogen solubility limit, to obtain a high blister growth rate. Micro X-Ray Diffraction (XRD), nano-hardness and Elastic Recoil Detection Analysis (ERDA) showed that the blisters contain a hydrogen gradient, with pure $\delta$-hydride phase close to the external surface over one third of the blister depth. thermo-diffusion
\end{abstract}

*Tel.: +33 1690839 43; e-mail: arthur.hellouin-de-menibus@cea.fr 
calculations showed these half thickness blisters should grow in only a few days in PWR conditions. Eventually, the Diffusion Equilibrium Threshold (DET) was defined as a criterion that limits the blister growth, and emphasizes that the hysteresis in the hydrogen solubility limit in zirconium must be taken into account to model hydrogen thermo-diffusion in zirconium alloys.

Keywords: Zirconium, Zircaloy-4, Hydrogen, Hydride Blister, thermodiffusion, Elastic Recoil Detection Analysis, X-ray Diffraction, Nano-Hardness

\section{Introduction}

PWR fuel cladding tubes are oxidized by the coolant water during exposure in a Pressurized Water Reactor (PWR). A fraction of the hydrogen released is absorbed and diffuses into the cladding. Hydrogen is sensitive to thermodiffusion, it diffuses in a thermal gradient toward the coldest temperature in zirconium alloys. This may lead to localized high hydrogen concentration on the cladding outer diameter in the form of hydride rims or blisters. Hydride rims are layers of uniform depth, that can reach 50-60 $\mu \mathrm{m}$, and cover a wide area on the tube azimutal and axial directions. On the other hand, blisters have an elliptic shape, are more localized on the tube external surface and are deeper, usually covering half of the cladding thickness. The hydrogen concentration is lower in rims than in blisters: single hydrides can still be distinguished inside a rim using high magnification SEM pictures, whereas that is not possible in blisters [1]. Both hydrogen defects (rims and blisters) reduce the cladding mechanical resistance [2], but blisters are generally deeper than rims. This study is limited to hydride blisters.

The blistering phenomenon was first reported in 1977 [3]. Blister induced failure was observed in 1983, when an axial crack developed in a CANDU Zircaloy-2 pressure tube along an array of hydride blisters on the external surface that was placed against the cold calendria tube [4]. This finding has motivated several experimental studies on hydride blister formation and growth, mainly focused on Zirconium- $2.5 \% \mathrm{Nb}[5,6,7,8,9,10]$, which is the material that replaced Zircaloy-2 alloy for pressure tubes in the CANDU reactors. In all these studies, hydride blisters were obtained in laboratories with thermo-diffusion setups.

Different thermal conditions for generating hydride blisters by thermodiffusion have already been tested in these previous studies (Table 1). The 
"protrusion height" is the height of the buldge that grows on the external diameter on the top of the blister. A large uncertainty is generally associated with the effective cold spot temperature as it is not directly measurable. In order to optimize the thermo-diffusion process, not only is the thermal gradient magnitude important, but also the temperature itself. If the thermal gradient is sharp but the cold spot is too cold, hydrogen diffusion near the cold spot would be limited because the diffusion coefficient would be too small. On the other hand, a high temperature with an insufficient thermal gradient would also result in a small hydrogen diffusion flux.

\begin{tabular}{|c|c|c|c|c|c|c|c|c|}
\hline Mat. & Geom. & Techni. & $\begin{array}{c}T_{C s} / T_{b} \\
\left({ }^{\circ} \mathrm{C}\right)\end{array}$ & $\begin{array}{c}\text { Duration } \\
(\text { Days })\end{array}$ & $\begin{array}{c}B D \\
(\mathrm{~mm})\end{array}$ & $\begin{array}{c}B D / 0.5 \varnothing \\
(\%)\end{array}$ & $\begin{array}{c}\text { PH/BD } \\
(\%)\end{array}$ & Ref. \\
\hline \multirow{7}{*}{$\begin{array}{c}\mathrm{Zr}- \\
2.5 \% \mathrm{Nb}\end{array}$} & Plate & Contact & $187 / 292$ & $14-21$ & $0.3-0.9$ & $59-95$ & 10 & Puls [5] \\
\cline { 2 - 9 } & Tube & $\begin{array}{c}\text { Compr. } \\
\text { air }\end{array}$ & $250 / 350$ & $<120$ & 0.25 & 14 & 12 & Leger [8] \\
\cline { 2 - 9 } & Tube & Contact & $\begin{array}{c}50- \\
70 / 300- \\
400\end{array}$ & - & $0.24 /$ day & 75 & - & $\begin{array}{c}\text { Singh } \\
{[10]}\end{array}$ \\
\cline { 2 - 9 } & $\begin{array}{c}\text { Tube } \\
\text { fragment }\end{array}$ & Contact & $170 / 390$ & $1.15-7$ & $0.4-1.2$ & $44-85$ & - & $\begin{array}{c}\text { Domizzi } \\
{[6]}\end{array}$ \\
\hline & $\begin{array}{c}\text { Tube } \\
\text { fragment }\end{array}$ & Contact & $180 / 370$ & $2.3-6.9$ & $0.15-0.7$ & - & 12.5 & $\begin{array}{c}\text { Cheong } \\
{[9]}\end{array}$ \\
\hline Zy4 & Tube & Contact & $\begin{array}{c}260- \\
335 / 375\end{array}$ & $0.25-1$ & $0.17-0.3$ & 70 & 22.2 & $\begin{array}{c}\text { This } \\
\text { study }\end{array}$ \\
\hline
\end{tabular}

$T_{C s}$ : temperature at the cold spot, $T_{b}$ : bulk temperature, $B D$ : blister depth,

$B D / 0.5 \varnothing$ : Ratio of blister depth to the blister half diameter,

$P H / B D$ : ratio of the protrusion height to the blister depth.

Remark 1: Singh et al. [10] used various cold spot / bulk temperatures but only the condition

$T_{C s} / T_{b}=50-70 / 300-400^{\circ} \mathrm{C}$ are reported for initial hydrogen content higher than $200 \mathrm{wppm}$.

Remark 2: the blister growth rate in Singh et al. [10] is measured with the protrusion growth rate but the $P H / B D$ ratio was not reported, it was converted to fill the table

with a $10 \% B H / B D$ ratio. This is questionable as Singh et al. [10] material texture is different from the one used in previous Canadian studies.

Remark 3: some blisters were also grown in Zircaloy-2 in Singh et al. [10] but their characterization was not reported.

Table 1: Conditions and results of laboratory grown blisters by thermodiffusion experiments.

In the case of PWRs, the effect of blisters on the cladding mechanical 
resistance was observed in the 90's in studies dealing with Reactivity Initiated Accidents (RIA) performed in research reactors such as CABRI [11] or NSRR [12]. It was also observed after burst and tensile tests on irradiated cladding tubes [13]. The blister formation mecanism in PWR irradiated cladding tubes is the formation of cold spots due to oxide spallation, that trigger hydrogen thermo-diffusion [13]. The blister geometry observed in Zircaloy-4 cladding tubes after reactor exposure is typically $1 \mathrm{~mm}$ to $5 \mathrm{~mm}$ in diameter and about half the thickness of the cladding tube (Figure 1 in addition to the analysis of the blisters reported in $[12,13,14,15,16,17,18,19])$. The formation of blisters on unirradiated Cold-Worked-Stress-Relieved (CWSR) Zircaloy4 specimens was experimentally achieved in the laboratory by applying a nickel coating on a given area of the sample surface to accelerate locally the hydrogen uptake during gaseous charging [14, 20, 21, 22].
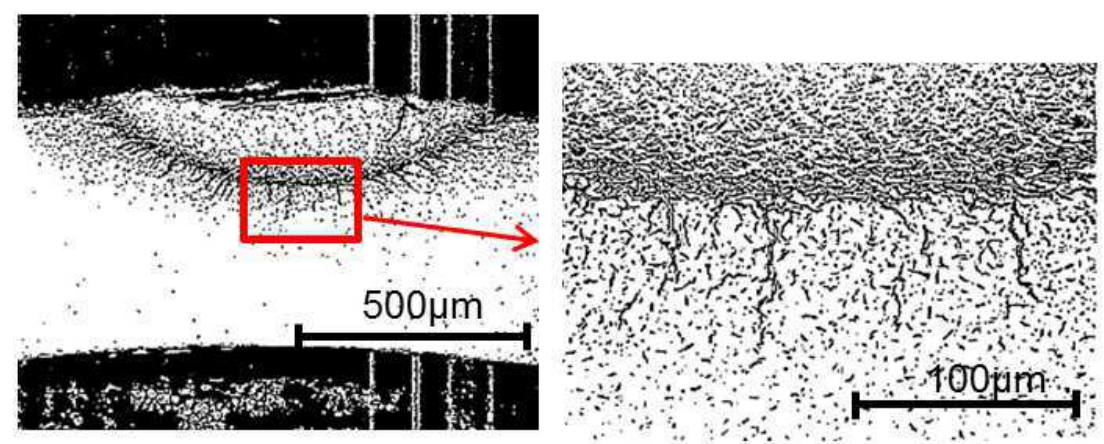

Figure 1: Optical microscopy pictures of hydride blisters on irradiated Zircaloy-4 claddings, courtesy of Toyoshi Fuketa (JAEA, Japan) [23].

In this paper, the Zircaloy-4 material used in the present study is first described, followed by the experimental procedures related to blisters formation and characterizations. The thermo-diffusion calculation procedures and their validations are then presented. Based on these calculations, the optimal condition to obtain a high blister growth rate by thermo-diffusion is determined. Then, the blister characteristics in terms of morphology, hydrogen concentration, hydrides crystallographic phases and nano-hardness are detailled. Afterwards, discrepancies between the laboratory grown blisters 
and in-reactor blisters are discussed. Eventually, a mechanism refered to as DET for Diffusion Equilibrium Threshold is proposed to explain why blister growth might be limited to a given depth in a thermal gradient.

\section{Material}

Samples were tubes of CWSR Zircaloy- 4 provided by CEZUS ${ }^{\circledR}$ company. They measured $9.5 \mathrm{~mm}$ in outer diameter and $0.57 \mathrm{~mm}$ in thickness. Their weight composition is 1.2 to $1.7 \% \mathrm{Sn}, 0.18$ to $0.24 \% \mathrm{Fe}, 0.07$ to $0.13 \% \mathrm{Cr}$, 0.1 to $0.14 \%$ O, Zr balance, according to the ASTM B 350.90 specification. The zirconium grain size was measured on 150x magnification polarized pictures taken with an optical microscope on polished radial-circumferential and radial-axial cross sections. The grain size was $2.5 \pm 0.7 \mu \mathrm{m}$ in the radial direction, $3.7 \pm 0.7 \mu \mathrm{m}$ in the circumferential one and of about $10 \mu \mathrm{m}$ in the tube axial direction. This material was obtained with the standard manufacturing route for CWSR Zircaloy-4. For this route, most of the the zirconium $\langle c\rangle$ axes are oriented at $\pm 30^{\circ}$ to the tube radial direction and the $<10 \overline{1} 0>$ direction is aligned with the tube axial direction [24].

Specimens were hydrided by gaseous charging at $400{ }^{\circ} \mathrm{C}$ for 3 hours to $310 \pm 80 \mathrm{wppm}$. The short gaseous charging duration at $400^{\circ} \mathrm{C}(<15$ hours $)$ did not induce either significant dislocations recovery or material recrystallization [25]. The cladding tube samples used to grow hydride blisters were 15 or $30 \mathrm{~mm}$ in axial length.

\section{Experimental procedures hydride blisters formation and characterization}

\subsection{Blister formation by thermo-diffusion}

\subsubsection{Thermo diffusion setup}

The technique consists in generating hydride blisters in pre-hydrided tubular samples by heating the tube and applying a cold spot on its external surface to reproduce the blister formation process in a PWR reactor. The specimens were heated from the inside by an Inconel 600 wire having a diameter of $1 \mathrm{~mm}$ and wound around a $304 \mathrm{~L}$ steel cylinder with a diameter of $5.5 \mathrm{~mm}$. The cold 
spot was generated by placing a $1 \mathrm{~mm}$ diameter oxygen free high conductivity copper rod against the cladding external surface (Figure 2). The copper rod was cooled by compressed air at the end opposite to that contacting the cladding. The contact force was fixed by a $500 \mathrm{~g}$ weight. The temperature of the cladding was monitored with 3 thermocouples located under the hydrided sample (Figure 2). No thermocouples were directly welded on the specimen surface, to avoid hydrogen diffusion toward the thermocouple locations. The bulk temperature was fixed at $375^{\circ} \mathrm{C}$ to prevent dislocations recovery [25]. The axial linear thermal flux provided by the heating rod was estimated to be $270 \mathrm{~W} / \mathrm{m}$ based on the measurement of the temperature at the external surface and the temperature inside the $304 \mathrm{~L}$ steel cylinder (a shielded thermocouple was placed at the rod center). This heat flux is about $2 \%$ of the typical linear heat flux in standard PWR conditions. After the heat treatment was completed, the cladding was cooled by turning off the heating rod, which resulted in a typical inverse exponential temperature decay with a mean cooling rate of $1000^{\circ} \mathrm{C} / \mathrm{h}$ from $375^{\circ} \mathrm{C}$ to $50^{\circ} \mathrm{C}$.

An initial $440^{\circ} \mathrm{C}$ isothermal temperature, before applying the cold spot, would have been required to integrally dissolve the $310 \mathrm{wppm}$ of hydrides that were initially homogeneously distributed in the as-received material. The choice to limit the bulk temperature to $375^{\circ} \mathrm{C}$ to limit dislocations recovery makes it impossible to dissolve all the hydrides before starting the blister growth process. The cold spot was nevertheless applied after a heating phase up to an isothermal temperature of $375^{\circ} \mathrm{C}$, in order to dissolve the highest content of hydrogen possible before the cold spot application, so as to promote the growth of a single blister (or possibly a few blisters) and not of a multiple array of blisters (this concept was described in [10]).

\subsection{Thermal field around the cold spot}

Prior to the blister formation campaign, a dedicated experiment with thermocouples and an infrared camera was performed to measure the temperature distribution on the cladding external surface for a given arbitrarily fixed cold spot temperature (Figure 2). The emissivity of the sample was determined to be $\varepsilon=0.67$ by comparing thermocouples and infrared measurements. This is close to $\varepsilon=0.62$ reported by Domizzi et al. [6] for oxidized Zr-2.5\% Nb. Note that a $10 \%$ error in the $\varepsilon=0.67$ emissivity value leads to a maximum $3.5 \%$ error in the measured temperature. This error is valid only in the explored temperature range and with the infrared (IR) camera configuration 


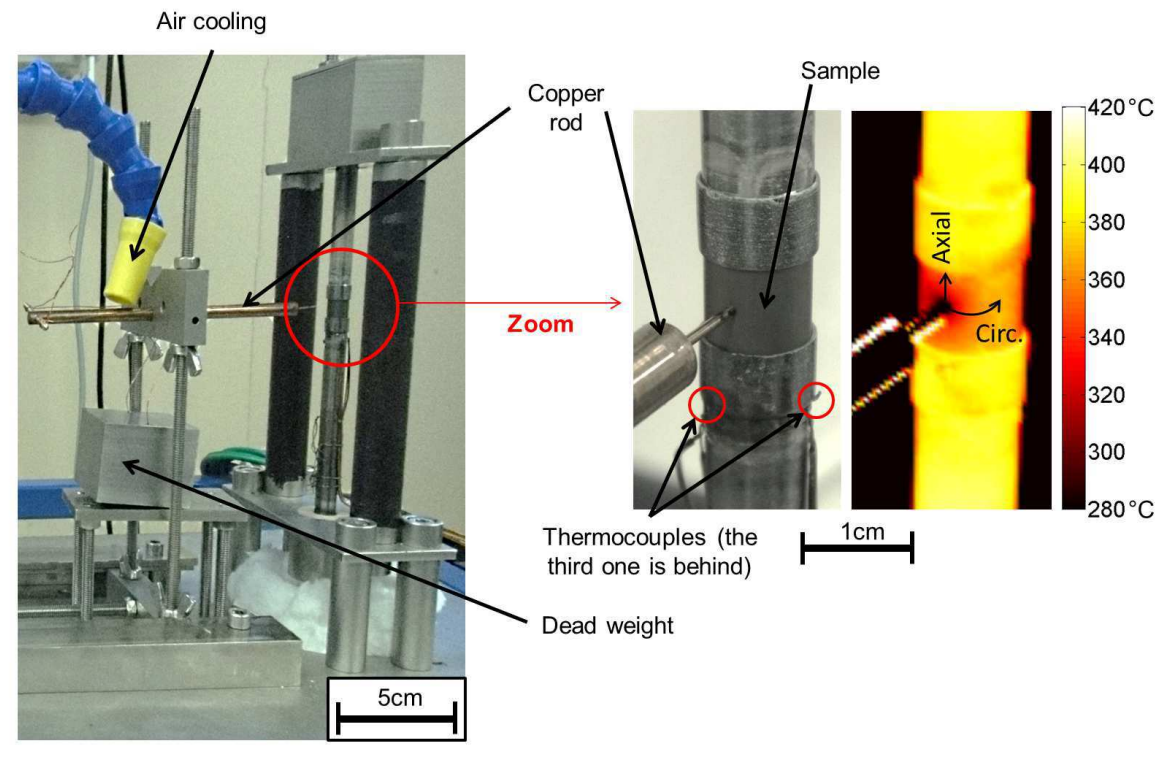

Figure 2: Cold spot setup and associated thermal cartography.

used. The temperature variations with distance in the axial ( $z$ ) and circumferential $(\theta)$ directions on the external surface were similar (profiles locations are showed on the infrared frame in Figure 2). They are described by the following equation, where $x$ is the distance to the cold spot:

$$
\left\{\begin{aligned}
T(x) & =T_{c}+K \log (\alpha x+1) \\
K & =\frac{T_{b}-T_{c}}{\beta} \\
\alpha & =\frac{e^{\beta}-1}{L_{\text {grad }}}
\end{aligned}\right.
$$

where $T(x)$ is the temperature profile (in ${ }^{\circ} \mathrm{C}$ ), $L_{\text {grad }}=8 \mathrm{~mm}$ is the distance in the axial direction between the cold spot and the regulation thermocouple, $T_{b}$ is the bulk temperature equal to $375^{\circ} \mathrm{C}$. Equation (1) satisfactorily describes the experimentally measured temperature distribution for a temperature at the cold spot estimated to be $T_{c}=260^{\circ} \mathrm{C}$, and with $\beta$, which controls the temperature evolution with the distance to the cold spot, equal to 9.7. thermo-diffusion calculations described later in section 4 were used to investigate if such a cold spot temperature is optimal regarding the blister growth rate. 


\subsection{Blister characterization}

The samples prepared for characterization were mechanically polished, finishing with a $1 \mu \mathrm{m}$ diamond paste, for all the measurements techniques described in this paper.

\subsubsection{Metallographic observations}

Metallographic observations were performed with a standard optical microscope and Scanning Electron Microscope (SEM). Hydrogen quantification and radial hydride quantification beneath the blister were performed by image analysis with a dedicated image analysis software developed at the CEA called "Hydruro" [26]. Hydrides tilted with a maximum $30^{\circ}$ angle from the radial direction were considered radial. Chemical etching with hydrofluoric acid to reveal the hydrides was only used for the "Hydruro" analysis.

\subsubsection{Shadowscopy}

Blister-induced protrusions were measured with a high technology automated shadowscopy device that makes diametrical measurements with a theoretical $0.1 \mu \mathrm{m}$ resolution. Samples were scanned with a $10 \mu \mathrm{m}$ axial step in $1^{\circ}$ angular increments.

\subsubsection{Micro ERDA}

The Elastic Recoil Detection Analysis (ERDA) is a nuclear method well adapted for hydrogen isotopes quantification. The technique and setup used have already been reported elsewhere [27]. In the present study, a $3 \mathrm{MeV} 4 \mathrm{He}^{+}$ incident beam with an intensity of $450 \mathrm{pA}$ was focused on the sample surface with a $15^{\circ}$ grazing angle. Hydrogen atoms ejected by elastic scattering were collected with a detector placed symmetrically, with a $15^{\circ}$ grazing angle. A particle detector placed at $170^{\circ}$ of the incident $4 \mathrm{He}^{+}$beam was used to collect the backscattered particles. The sample thickness analyzed was about $500 \mathrm{~nm}$. The sample was scanned on the radial-circumferential plane. The beam size was $3 \times 3 \mu \mathrm{m}^{2}$ and the surface was scanned with a $2 \times 2 \mu \mathrm{m}$ step $\left(2 \times 8 \mu \mathrm{m}\right.$ due to the grazing angle). Typical $300 \times 400 \mathrm{px}^{2}$ matrix were acquired during a $2 \mathrm{~h}$ to $3 \mathrm{~h} 30$ scan duration. Pixel per pixel conversion of these spectrums to hydrogen concentration were based on spectrum simulations 
performed with SIMNRA [28]. Local heating due to incident ion beam interaction with the sample was limited to a few degrees by the low incident current and the beam scanning on the analysed area [29]. The constant rate of hydrogen atom counts over the whole measurement period confirmed that hydrogen desorption was negligible. To quantify the accuracy of ERDA at high hydrogen content, the hydrogen concentration of highly hydrided Zircaloy-4 and unalloyed zirconium coupons were determined by fusion and by ERDA. The highest discrepancy in the hydrogen quatification between the two techniques was $2.5 \%$.

\subsubsection{Micro X-ray diffraction}

Micro XRD analyses were performed on a setup developed at the CEA/LAPA (Figure 3). A molybdenum anode was used to produce a flux of $10^{6}$ photons per second at $17.48 \mathrm{keV}$ and $\lambda_{K \alpha 1}=0.0709 \mathrm{~nm}$. The sample was tilted with a $8^{\circ}$ angle from the incident beam that gives a $360 \times 50 \mu \mathrm{m}^{2}$ effective beam size on the sample. Reflected X-rays were collected on a 2D detector image plate that was subsequently scanned with a $50 \times 50 \mu \mathrm{m}^{2}$ step in a molecular dynamic scanner. The half Debye rings obtained were integrated using Fit2D [30].



(a)

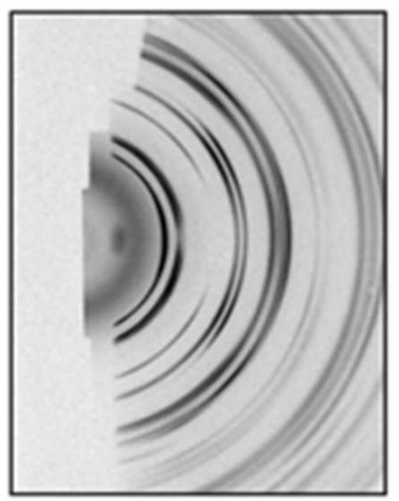

(b)

Figure 3: (a) Micro XRD setup used, (b) half Debye rings obtained. 


\subsubsection{Nano-hardness}

Nano-hardness was measured following two profiles lines across the thickness in the center of a $217 \mu \mathrm{m}$ deep blister on the radial circumferential plane with a standard Berkovitch indenter $\left(142.3^{\circ}\right)$ using a Nano-indenter $\mathrm{XP}^{\circledR}$ with a $10 \mathrm{mN}$ load. Indentations were spaced every $3.6 \mu \mathrm{m}$ to obtain a high spatial resolution. Results should therefore only be considered in a relative sense as this pitch is smaller than the spacing recommended by the NF-EN ISO 14577-1 standard. The elastic modulus was measured by three unloading phases during the indentation process. The Poisson ratio was fixed to 0.3 for both $\delta$-hydride and zirconium (close to the 0.32 Poisson ratio found by Yamanaka et al. [31] for both the $\delta$-hydride and zirconium).

\section{Numerical procedures thermo-diffusion cal- culations}

\subsection{Model and hypothesis}

Hydrogen diffusion in a thermal and a concentration gradient can be modelled in the framework of the thermodynamic of the irreversible processes by the following equation [32]:

$$
J=-D \frac{d C}{d x}-\frac{D C Q^{*}}{R T^{2}} \frac{d T}{d x}
$$

where $J$ is the hydrogen flux $\left(\mathrm{kg} / \mathrm{m}^{2} / \mathrm{s}\right), D=D_{0} e^{-\frac{Q_{D}}{R T}}$ is the diffusion coefficient of hydrogen in solid solution in $\alpha$-zirconium $\left(\mathrm{m}^{2} / \mathrm{s}\right), x$ is the distance $(\mathrm{m}), Q^{*}$ is the heat of transport $(\mathrm{J} / \mathrm{mol}), R$ is the gas constant equal to $8.314 \mathrm{~J} / \mathrm{mol} / K$ and $T$ is the temperature $(\mathrm{K})$. The hydrogen concentration in solid solution $\left(\mathrm{kg} / \mathrm{m}^{3}\right)$ is defined by

$$
C=C_{0} e^{-\frac{Q_{C}}{R T}}
$$

Both the concentration gradient and thermal gradient terms enhance hydrogen diffusion toward the cold spot because the heat of transport coefficient $Q^{*}$ is positive for hydrogen thermo-diffusion in zirconium $\alpha$-Zr or $\beta$ - Zr [33]. The equation (4) shows that the ratio of the Fick $(D d C / d x)$ to the thermal 
gradient term $\left(D C Q^{*} / R T^{2} \times d T / d x\right)$ is equal to the ratio of the activation energy of the hydrogen in solid solution (equal to $Q_{C}=32 \mathrm{~kJ} / \mathrm{mol}$ if using the Terminal Solid Solubility in Dissolution referred to as TSSD [34]) to the heat of transport for thermo-diffusion $\left(Q^{*}=25 \mathrm{~kJ} / \mathrm{mol}\right.$ by averaging data from $[34,35,36,37,38,39,40,41])$.

$$
\left\{\begin{aligned}
J & =-D\left(\frac{d C}{d x}+\frac{C Q^{*}}{R T^{2}} \frac{d T}{d x}\right) \\
& =-D_{0} e^{-\frac{Q_{D}}{R T}\left(\frac{C_{0} Q_{C}}{R T^{2}} \frac{d T}{d x} e^{-\frac{Q_{C}}{R T}}+\frac{C_{0} Q^{*} e^{-\frac{Q_{C}}{R T}}}{R T^{2}} \frac{d T}{d x}\right)} \\
& =-\frac{D_{0} C_{0} e^{\frac{-\left(Q_{D}+Q_{C}\right)}{R T}} \frac{d T}{R T^{2}}\left(Q_{C}+Q^{*}\right)}{d x}
\end{aligned}\right.
$$

Therefore, the Fick and thermo-diffusion contributions to the hydrogen diffusion flux under a thermal gradient are of the same order of magnitude $\left(Q_{c} / Q^{*}=32 / 25=1.28\right)$. Equation $(2)$ was solved together with mass conservation expressed as:

$$
\frac{d C}{d t}=\frac{d J}{d x}
$$

which was solved with a finite difference scheme in 1D cartesian coordinates

$$
\frac{\Delta C(x)}{d t}=\frac{J(x+d x)-J(x)}{d x}
$$

or spherical coordinates:

$$
\frac{\Delta C(x)}{d t}=\frac{J(x+d x)-J(x)}{d x}+\frac{2 J(x+d x)}{x}
$$

The temperature was considered to remain constant during the diffusion process, which was justified by the limited drop of $10 \%$ to $15 \%$ of the thermal conductivity when zirconium transforms into $\delta$-hydrides [42]. In addition, it was assumed that the temperature evolution due to the protrusion growth was negligible. The boundary conditions were defined such that no hydrogen uptake and desorption are considered.

Hydride dissolution and precipitation kinetics are assumed to be controlled by the hydrogen diffusion kinetics, and thus are not taken into account in the calculations. This assumption was validated by Kearns' studies 
[43] for hydride dissolution. Regarding hydride precipitation, Zanellato et al. [44] performed in situ XRD experiments showing that the TSSP (Terminal Solid Solubility in Precipitation) is unaffected by the cooling rate below $10^{\circ} \mathrm{C} / \mathrm{min}$. Considering a cooling from $400^{\circ} \mathrm{C}$ to $390^{\circ} \mathrm{C}$, a $10^{\circ} \mathrm{C} / \mathrm{min}$ cooling rate is equivalent to a hydride precipitation rate of $25 \mathrm{wppm} / \mathrm{min}$, which is about half the hydride precipitation rate measured by Une et al. [45] (about $60 \mathrm{wppm} / \mathrm{min}$ at $400^{\circ} \mathrm{C}$ ). Thus, the TSSP independence from the cooling rate below $10^{\circ} \mathrm{C} / \mathrm{min}$ seems consistent. To conclude, hydride dissolution and precipitation kinetics can be neglected during the slow blister growth by hydrogen thermo-diffusion.

The model was solved using one (the TSSD - Terminal Solid Solubility in Dissolution) or two solubility limits (the TSSD and the TSSP) to account for the hysteresis of the solubility limit of hydrogen in zirconium between hydrides dissolution and precipitation [46]. The diffusion equations are the same for both cases. The hysteresis was taken into account (or not) when the hydrogen in solid solution was updated after each calculation step. When considering one solubility limit, the hydrogen concentration in solid solution was computed with the equation, in 1D:

$$
C_{i}^{t}=\min \left(C t o t_{i}^{t-1}+\frac{d C_{i}^{t-1}}{d t} \times \Delta t, T S S D\right)
$$

where $C_{i}^{t}$ is the concentration in solid solution at the time $t$ in the element $i$, $\mathrm{Ctot}_{i}^{t-1}$ is the total hydrogen concentration (hydrogen in solid solution plus precipitated hydrides) at the time $t-1$ in the element $i$, and $\Delta t$ is the time step. When considering two solubility limits, the following partition was used for each element:

$\left\{\begin{array}{l}C_{i}^{t}=\min \left[C_{i}^{t-1}+\frac{d C_{i}^{t-1}}{d t} \Delta t, \min \left(C_{t o t}^{t-1}+\frac{d C_{i}^{t-1}}{d t} \Delta t, T S S P\right)\right] \text { for } \frac{d C_{i}^{t-1}}{d t}>0 \\ C_{i}^{t}=\max \left[C_{i}^{t-1}+\frac{d C_{i}^{t-1}}{d t} \Delta t, \min \left(C t o t_{i}^{t-1}+\frac{d C_{i}^{t-1}}{d t} \Delta t, T S S D\right)\right] \text { for } \frac{d C_{i}^{t-1}}{d t} \leq 0\end{array}\right.$

Preliminary calculations showed that simulations converged for a $20 \mu \mathrm{m}$ element size and an automatic time step set up so the hydrogen content variation between two time steps was lower than $0.1 \mathrm{wppm}$. The $0.1 \mathrm{wppm}$ maximum hydrogen concentration variation criterion results in a time step of about half the usual criterion for diffusion processes $\Delta t=\frac{L}{2 D}$ with $L$ is the element size and $D$ is the diffusion coefficient at the highest temperature in the considered thermal gradient. 


\subsection{Validity checking of the hydrogen thermo-diffusion code}

The validity of the model was checked against two thermo-diffusion experiments carried out by Sawatzky [35] and Kammenzind et al. [34]. Two material parameter sets were used (Table 2). The first one was the one used by Marino [47] to simulate the Sawatzky [35] thermo-diffusion experiment. The second was identified by Kammenzind et al. [34] for Zircaloy-4, except the heat of transport $\left(Q^{*}\right)$ that is an average of several results reported in the litterature. The diffusion coefficient of the first set is abnormally high; it is about $80 \%$ greater to the one of the second set in the range $300{ }^{\circ} \mathrm{C}$ to $400{ }^{\circ} \mathrm{C}$.

\begin{tabular}{|c|c|c|c|}
\hline Parameters set & Parameter & Expression & Ref. \\
\hline \multirow{3}{*}{ Set 1 - Sawatzky } & $\mathrm{D}_{0}\left(\mathrm{~mm}^{2} / \mathrm{s}\right)$ & $0.217 e^{-35028 /(R T)}$ & {$[48]$} \\
& TSSD $(\mathrm{wppm})$ & $99000 e^{-34485 /(R T)}$ & {$[49]$} \\
& $\mathrm{TSSP}(\mathrm{wppm})$ & - & - \\
& $Q^{*}(\mathrm{~kJ} / \mathrm{mol})$ & 25.1 & {$[35]$} \\
\hline \multirow{5}{*}{ Set 2 - Kammenzind } & $\mathrm{D}_{0}\left(\mathrm{~mm}^{2} / \mathrm{s}\right)$ & $0.08 e^{-33252 /(R T)}$ & {$[34]$} \\
& $\mathrm{TSSD}(\mathrm{wppm})$ & $66000 e^{-32144 /(R T)}$ & {$[34]$} \\
& $\mathrm{TSSP}(\mathrm{wppm})$ & $31000 e^{-25239 /(R T)}$ & {$[34]$} \\
& $\mathrm{Q}^{*}(\mathrm{~kJ} / \mathrm{mol})$ & 25.0 & Average \\
\hline
\end{tabular}

Table 2: Material parameters considered for the thermo-diffusion calculations.

Calculations were performed with a hydrogen effective diffusion coefficient $D_{\alpha+\delta}$ in a $\alpha+\delta$ mixture. The effective diffusion coefficient was calculated for each element at each time step with the diffusion coefficient in unhydrided zirconium alloy $D$ and the $\delta$-hydrides volumetric fraction $f_{\delta}$ :

$$
D_{\alpha+\delta}=D\left(1-f_{\delta}\right)
$$

Previous work showed that hydrogen can diffuse in hydrides (Korn et al. [50]) but it is about 3 times lower in $\delta$ hydrides than in zirconium and was therefore neglected.

The Sawatzky [35] experiment consisted of applying a linear temperature gradient from $130^{\circ} \mathrm{C}$ to $477^{\circ} \mathrm{C}$ on a $25 \mathrm{~mm}$ Zircaloy-2 sample homogeneously hydrided to $130 \mathrm{wppm}$. The hydrogen migration was calculated in the present study with a 1D mesh composed of $0.05 \mathrm{~mm}$ elements. The simulation with one solubility limit fits the experimental data correctly (plain line in Figure 
4(a)), as reported by Marino [47] (triangles in Figure 4(a)). The calculation performed using the second set of material parameters in Table 2 results in a hydrogen distribution that still roughly fits the experimental measurements (dashed line in Figure 4(a)). The peak of the distribution progressively moves towards the cold spot, and reaches it when the system is at equilibrium. The Sawatzky [35] experiment was then simulated with two solubility limits (dotted line in Figure 4(a)). It was assumed that the test temperature was reached by heating as Sawatzky did not report any overheating prior to the experiment. The hydrogen distribution with two solubility limit does not fit the experimental data.

The Kammenzind et al. [34] experiment consisted of applying a linear thermal gradient of $8.05^{\circ} \mathrm{C} / \mathrm{mm}$ from $309^{\circ} \mathrm{C}$ at the cold spot on a $25 \mathrm{~mm}$ long Zircaloy-4 sample homogeneously hydrided (experimental conditions and results were taken in Figure 23 in [34]). The hydrogen content was not explicitly given in the Kammenzind et al. publication [34]. By integrating the final hydrogen distribution and assuming no hydrogen losses took place during the experiment, the initial hydrogen content was assumed to be $120 \mathrm{wppm}$. The 1D mesh used consisted of $0.05 \mathrm{~mm}$ elements, similarly to the one used to simulate the Sawatzky experiment. Kammenzind et al. [34] did not specify whether the test temperature was reached by heating or cooling. The calculations were thus performed for both cases. The second set of material parameters in Table 2 was used. The hydrogen distribution obtained with two solubility limits closely fits the experimental results regardless of whether the temperature was reached in heating or cooling (dashed and dotted line in Figure 4(b)). The agreement between calculated and experimental hydrogen distributions was slightly better than the one reported by Kammenzind et al. [34] (triangle in Figure 4(b)), but the reason for the better agreement is still unknown. The one solubility calculation results in a different hydrogen distribution (dashed line in Figure 4(b)).

To conclude, the simulation of Sawatzky [35] and Kammenzind et al. [34] thermo-diffusion experiments gave satisfactory results but do not delineate whether one or two solubility limits should be used to model hydrogen diffusion in a time independent thermal gradient. This question will be further discussed in the discussion section. 




(a)

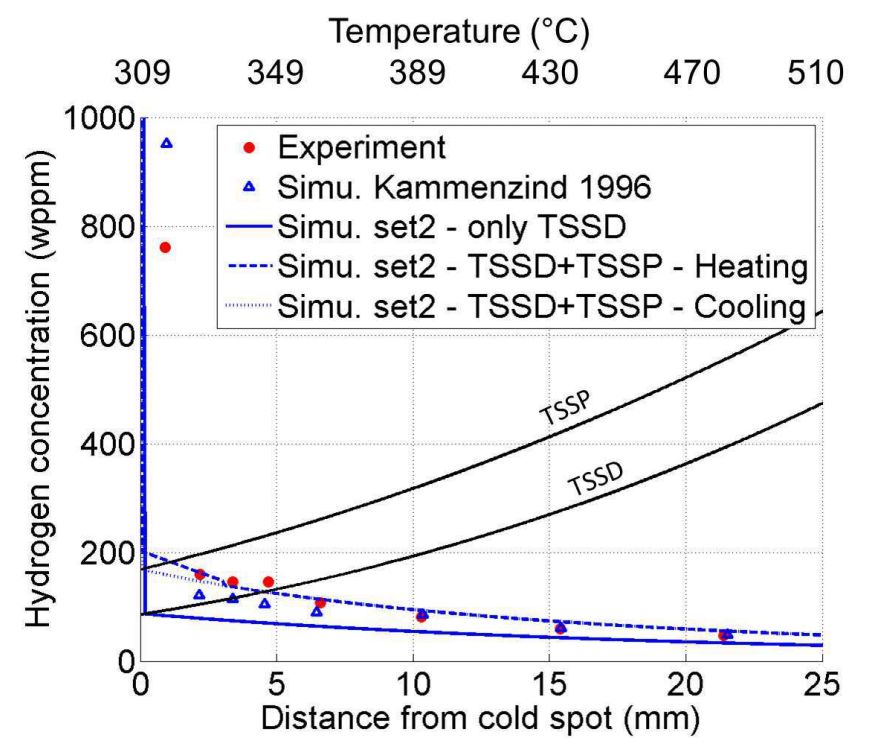

(b)

Figure 4: Calculated hydrogen distributions and comparison with experimental results corresponding to (a) a Sawatzky [35] experiment and (b) a Kammenzind et al. [34] experiment. 


\section{Results}

The blister growth conditions and blister characterizations of the present study are included in Table 1 for comparison purposes.

\subsection{Optimized thermal conditions for blister formation}

thermo-diffusion calculations were performed to identify the couple cold-spot temperature and far-field temperature that optimizes the blister growth rate. The hydrogen flux was solved using spherical coordinates. In the calculation, the thermal gradient was applied only over a $8 \mathrm{~mm}$ length that corresponds to the axial distance between the cold spot and the regulation thermocouple (Figure 5). A homogeneous temperature was fixed on the remaining $7 \mathrm{~mm}$, which acts in the calculation as an infinite source of hydrogen. Calculations were performed with the second material set in Table 2. A $20 \mu \mathrm{m}$ mesh size was fixed based on a preliminary convergence study. The result of these calculations was the evolution of the blister size as a function of the temperature at the cold spot, for a $375^{\circ} \mathrm{C}$ far field temperature and for the specific temperature distribution defined by equation (1) (temperature distributions for various cold spot temperature are shown in Figure 6(a)). An element was arbitrarily considered to be part of the blister when its concentration reached $85 \%(\approx 14500 \mathrm{wppm})$ of the $\alpha+\delta \rightarrow \delta$ boundary at $25^{\circ} \mathrm{C}$. ERDA results described hereafter would justify this $85 \%$ threshold. However, the sensitivity of the blister growth evolution to this $14500 \mathrm{wppm}$ threshold for the definition of the blister is limited because the variation of the blister size for a given duration is limited to $\pm 17 \%$ if the threshold is chosen in the range $12000 \mathrm{wppm}-17000 \mathrm{wppm}$. Considering only one solubility limit (TSSD) or two solubility limits with the thermal gradient reached in heating (TSSD+TSSP with the initial hydrogen solid solution equal to the TSSD) or cooling (TSSD+TSSP with the initial hydrogen solid solution equal to the TSSP) results in rather similar blister growth kinetic (maximum discrepancy of about $30 \%$ up to 50 hours thermo-diffusion duration - figure 6(b)). Thus, only the TSSD+TSSP ini=TSSP case will be considered from now on. The time to obtain a $0.1 \mathrm{~mm}, 0.2 \mathrm{~mm}$ or $0.3 \mathrm{~mm}$ blister for a $375^{\circ} \mathrm{C}$ bulk temperature depends on the cold spot temperature (Figure 6(c)). Interestingly, a cold spot temperature variation between 150 to $260^{\circ} \mathrm{C}$ results in a similar blister growth rate (difference in duration $<8 \%$ for a $0.3 \mathrm{~mm}$ deep blister).

The arbitrarily fixed air cooling temperature and flux that allows the tem- 




Figure 5: 1D spherical mesh used for the thermo-diffusion calculation.

perature to reach an estimated $260^{\circ} \mathrm{C}$ at the cold spot was thus a good choice to obtain a high blister growth rate. Using these experimental conditions, blisters measuring $290 \mu \mathrm{m}$ in depth were obtained after $24 \mathrm{~h}$ thermo-diffusion experiments. This blister growth rate was not very different from the one obtained by Domizzi et al. [6] - only $40 \%$ slower for a $24 \mathrm{~h}$ grown blister (Figure 6(d)). Domizzi et al. [6] used a cold spot temperature of $170^{\circ} \mathrm{C}$ and a bulk temperature of $390^{\circ} \mathrm{C}$, instead of $375^{\circ} \mathrm{C}$ in the present study, which induces an increase in the blister growth rate of $16 \%$ based on calculations performed in the present study.

The thermo-diffusion calculation showed that a $0.3 \mathrm{~mm}$ deep blister will be obtained after 47 hours, which was twice the experimentaly measured duration (24 hours). Nevertheless, the variability of the material parameters concerning the hydrogen diffusion and solubility limit is high from one study to the other. For instance, more than $50 \%$ variability in the diffusion coefficient has been reported (comparison of data in $[34,35,51,52,53$, $54,55,56,57,58,59,60])$. A calculation considering an increase by $30 \%$ of the diffusion coefficient results in a $300 \mu \mathrm{m}$ blister in 20h (Figure 6(d)). Therefore, the quantitative estimate of the blister growth rate obtained by thermo-diffusion calculations in the present study, without any adjustable variable, is considered satisfactory. 


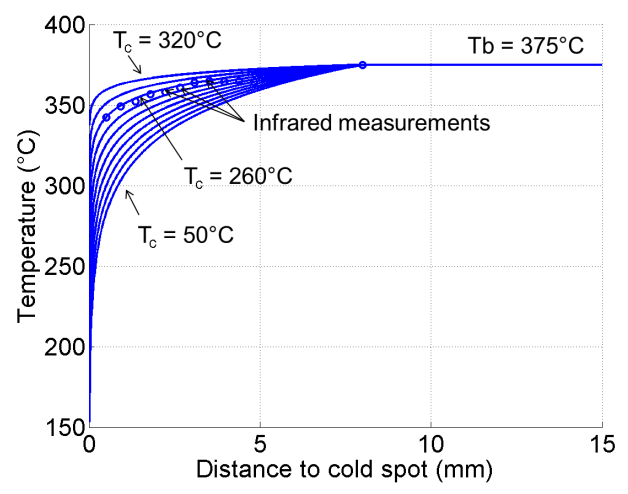

(a)

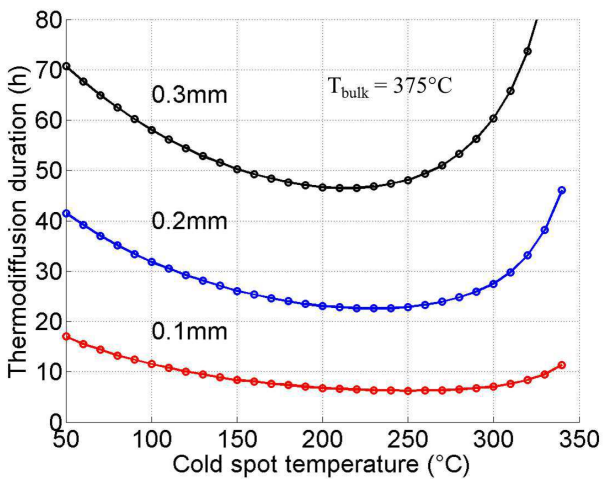

(c)

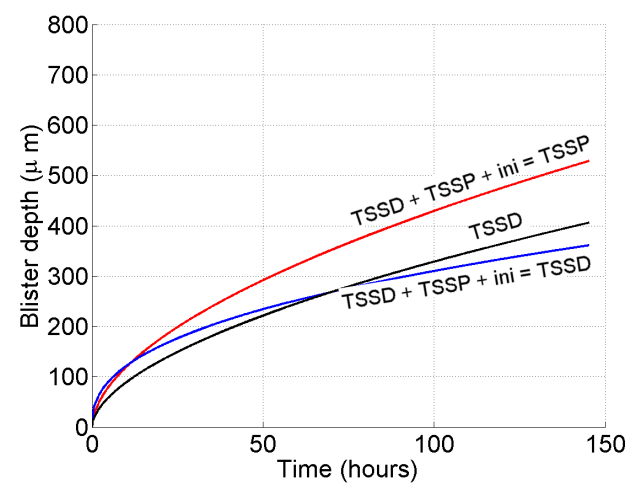

(b)

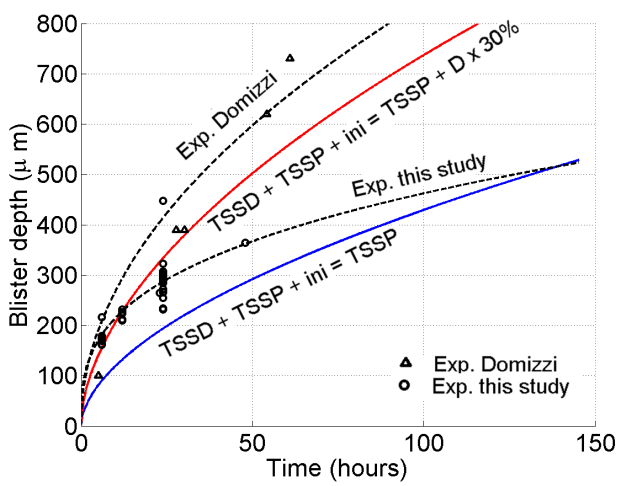

(d)

Figure 6: thermo-diffusion calculations results with a $375^{\circ} \mathrm{C}$ far field temperature: (a) temperature profile from the equation (1) for different cold spot temperatures, (b) effect of the solubility limit model on the blister growth kinetics estimate with the thermal field defined by equation 1 and a cold spot equal to $260^{\circ} \mathrm{C}$, (c) thermo-diffusion duration required to obtain a $0.1 \mathrm{~mm}$, $0.2 \mathrm{~mm}$ and $0.3 \mathrm{~mm}$ deep blister, and $(\mathrm{d})$ comparison of the blister growth rate between Domizzi et al. [6] with the present study, and with the thermodiffusion estimate (blue), and considering a 30\% increased diffusion coefficient (red). 


\subsection{Blister characterization}

\subsubsection{Blister morphology}

The blister lenticular shape in the cladding thickness and induced protrusion on the external diameter are shown in Figure 7(a). The blister depth referred in the present study was the distance from the highest point of the protrusion till the interface blister-matrix. A transition zone referred to as sunburst is located between the blister and the zirconium matrix. The sunburst consists of a mix of thin and large radial and circumferential hydrides. The boundary between the sunburst and the matrix is not easy to determine on a metallographic section (it is defined later with the ERDA measurements). Blister depth measurement performed in the present study does not include the sunburst. The depth of the blister obtained for a given diffusion duration has been assessed on 8 samples by progressive polishing in the axial direction and frequent measurement of the blister depth (Figure $7(\mathrm{a})$ ). The protrusion and blister diameter were determined by shadowscopy for all the blisters obtained (Figure $7(\mathrm{~b})$ and $7(\mathrm{c})$ ). It was found the ratio of the protrusion height to the blister depth (as defined in the present study) was equal to $22.2 \%$ regardless of the diffusion duration between $6 \mathrm{~h}$ to $24 \mathrm{~h}$ (Figure $7(\mathrm{~d})$ ). A ratio equal to $21.5 \pm 1.2 \%$ was obtained by post-mortem SEM measurements on 17 samples fractured after mechanical tests (not described in the present publication).

Image analysis with "Hydruro" showed that the hydrogen concentration was about 1000 wppm right beneath the blister and decreases to $395 \mathrm{wppm}$ on average on the circumferential section (Figure 8). Moreover, the radial hydride fraction close to the blister was equal to $23 \%$ based on "Hydruro" measurements.

All observed blisters at room temperature after the blister growth experiment were cracked, as reported in previous studies [5, 6]. The size and

number of cracks visible on the tube external surface were greater for deeper blisters, but without any specific spatial repartition (no more axial than circumferential cracks). 


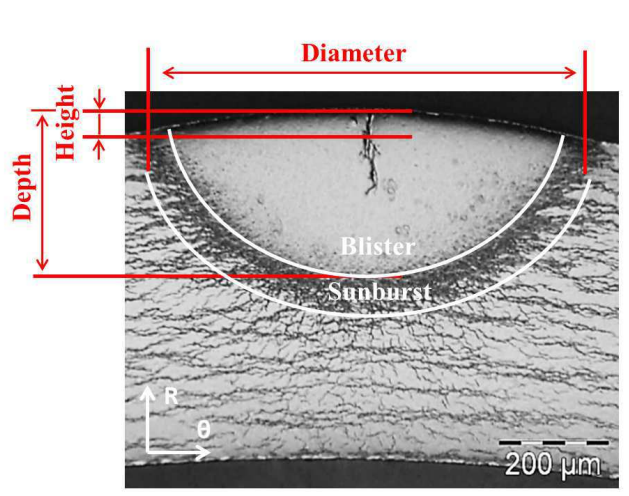

(a)

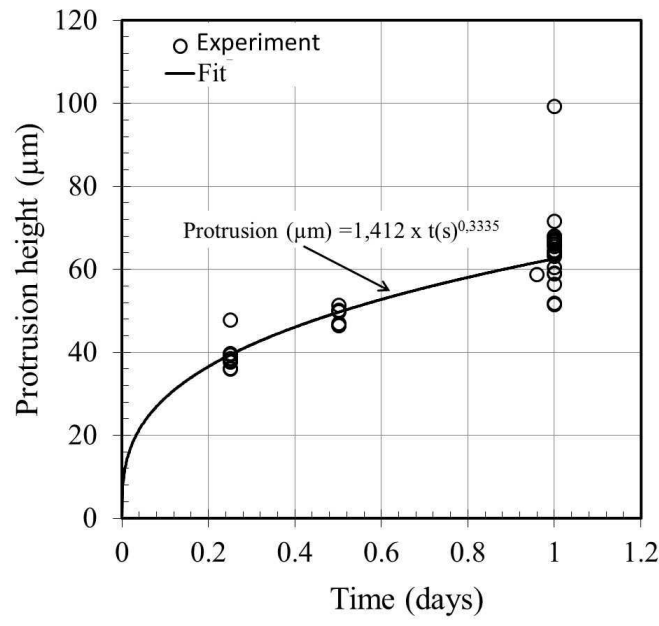

(c)

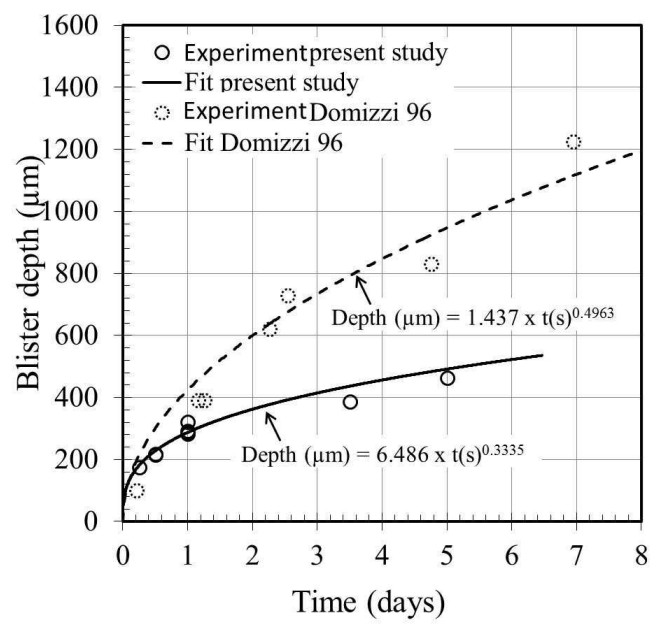

(b)

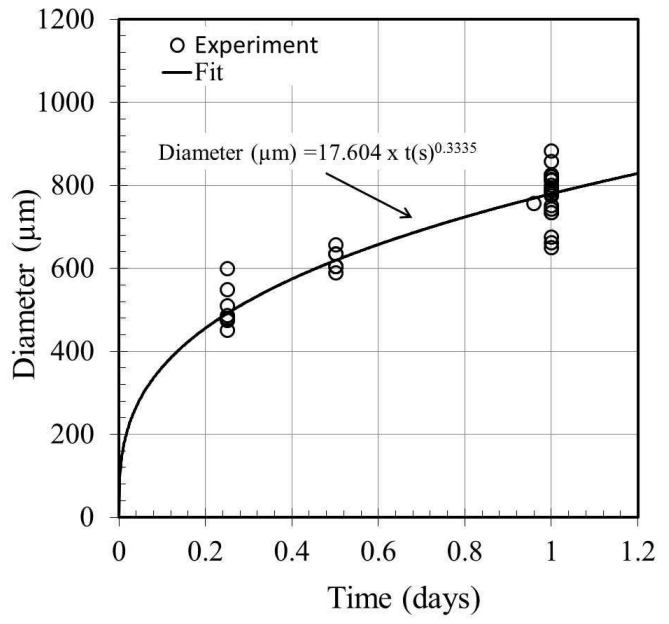

(d)

Figure 7: (a) Blister morphology definition and evolution with the thermodiffusion duration of the (b) blister depth, (c) protrusion height and (d) blister diameter. 


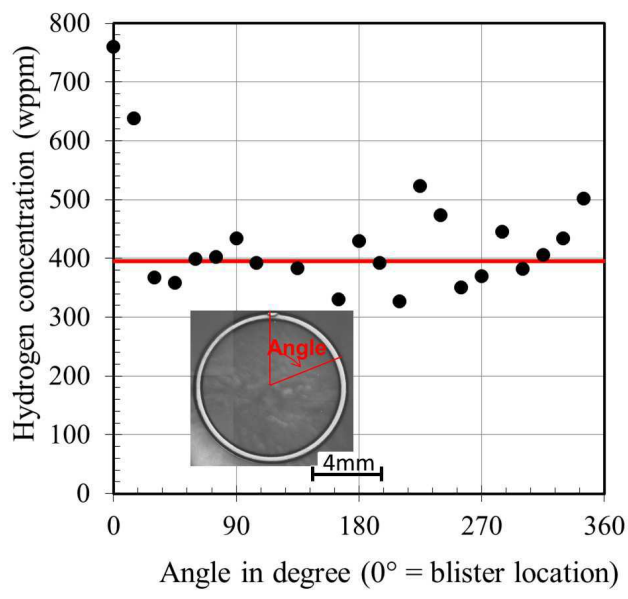

(a)

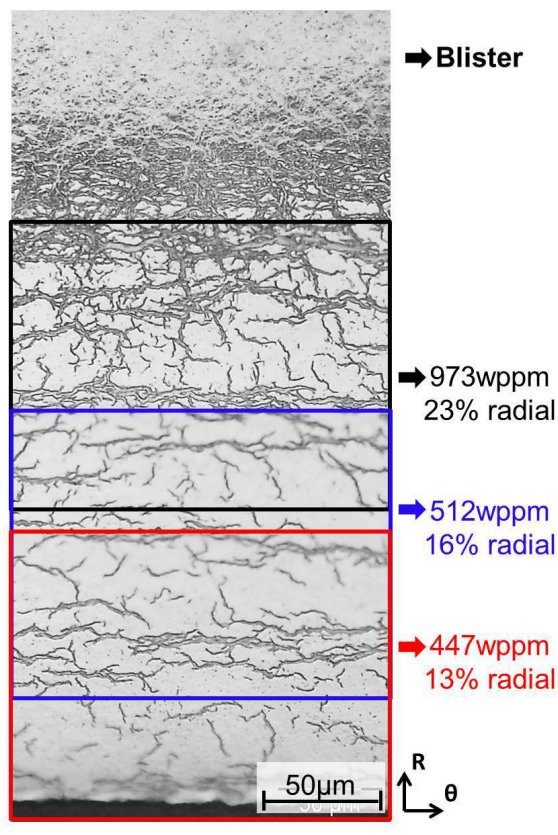

(b)

Figure 8: (a) Hydrogen content all over the cross section and (b) radial hydrides fraction under the blister, both based on Hydruro measurements. 


\subsubsection{Hydrogen quantification by ERDA}

The global hydrogen concentration cartography obtained after data processing corresponds to three $800 \times 300 \mu \mathrm{m}^{2}$ partially overlapped acquisitions on a $300 \mu \mathrm{m}$ deep blister (Figure 9(a)). To reduce data noise, the cartography was filtered with an empirically chosen $5 \times 5$ Gaussian filter. The stoichiometry of $\delta$-hydrides considered at $25^{\circ} \mathrm{C}$ is not $Z r H_{1.66}$ but $Z r H_{1.557}$, as suggested by Puls [46] and confirmed with Thermo-Calc software [61] thermodynamical calculations reported in [62]. The volumetric fraction was calculated with a zirconium density equal to $6.500 \mathrm{~g} / \mathrm{cm}^{3}$ [63] and a $\delta$-hydride density equal to $5.646 \mathrm{~g} / \mathrm{cm}^{3}$ [64]. Figures $9(\mathrm{~b})$ and $9(\mathrm{c})$ show the hydrogen distribution along the vertical and horizontal black lines displayed in Figure 9(a). The hydrogen volumetric fraction is higher than at the $\alpha+\delta \rightarrow \delta$ transition point at $25^{\circ} \mathrm{C}$ on about $100 \mu \mathrm{m}$ from the external diameter on the vertical distribution profile (Figure 9(b)). The hydrogen concentration decreases slightly with the blister depth and reaches $85 \% \delta$-hydride volumetric fraction close to the sunburst. This justifies the blister threshold defined at $85 \%$ hydrogen volumetric fraction used in the thermo-diffusion calculations. This hydrogen concentration distribution is not intrinsic of hydride blisters in general, and different temperature gradients would likely result in different hydrogen distributions. Based on the hydrogen distribution along the vertical line, the sunburst size is $77 \mu \mathrm{m}$ for this $300 \mu \mathrm{m}$ deep blister. Hydrides in the bulk erroneously seem to have lower hydrogen concentration than $\delta$-hydrides because the pixel size is not small enough to only contain hydrides. The nonsaturation of the blister at 100\% volumetric fraction of $\delta$-hydrides confirms that hydrogen can still diffuse in $\delta$-hydrides, in agreement with Korn and Goren [50]. 


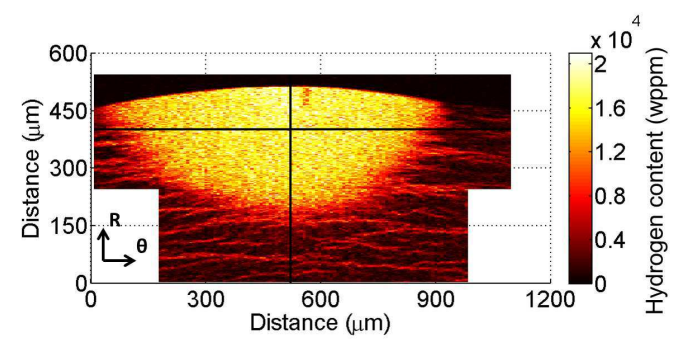

(a)

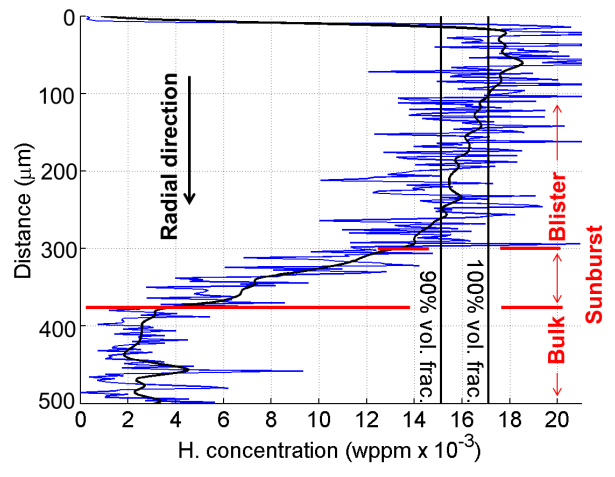

(b)

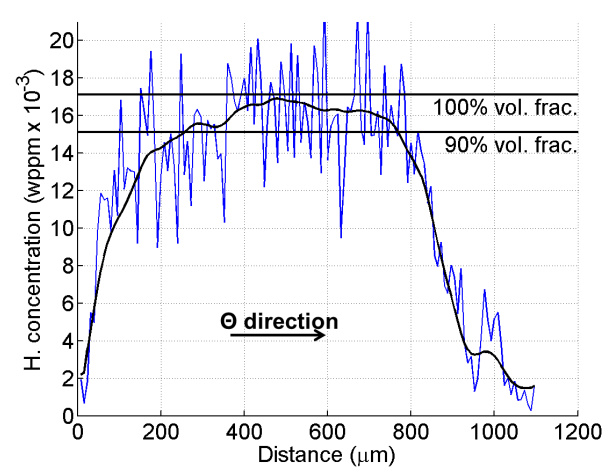

(c)

Figure 9: (a) ERDA cartography in wppm and distribution along the (b) horizontal and (c) vertical line. The blue line is the rough signal, the black line corresponds to the gaussian filtered signal. 


\subsubsection{Hydrides crystallographic phases}

Micro-XRD measurements were performed on the radial-circumferential plane on the same sample that was used for ERDA measurements. Two runs were performed scanning at $20 \mu \mathrm{m}$ and $50 \mu \mathrm{m}$ from the outer diameter (in red and orange respectively in Figure 10), and a reference run was performed in the hydrided matrix outside the blister (in black). The reference run confirmed the expected CWSR Zircaloy-4 texture, in which the (101) peak is more intense than the (100) peak, and the intensity at the (002) peak is null. The first scan includes intense bismuth rays (in purple in Figure 10) that correspond to the coating. Therefore, the discrepancy in peak height should not be directly interpreted because the blister scanned area is not the same for both scans. The diagram of the first run at $20 \mu \mathrm{m}$ shows no (101) or (110) zirconium peaks, while a $\delta$-hydride peak is present at (311) and a limited one at (220). The second run shows small zirconium peaks at the (101) or (110) location. This shows that the transformation $\alpha+\delta \rightarrow \delta$ is complete on the outer part of the blister. Neither $\varepsilon$ nor $\gamma$ hydride phases were detected either in this micro-XRD characterization or in macro-XRD characterizations not described in the present paper.

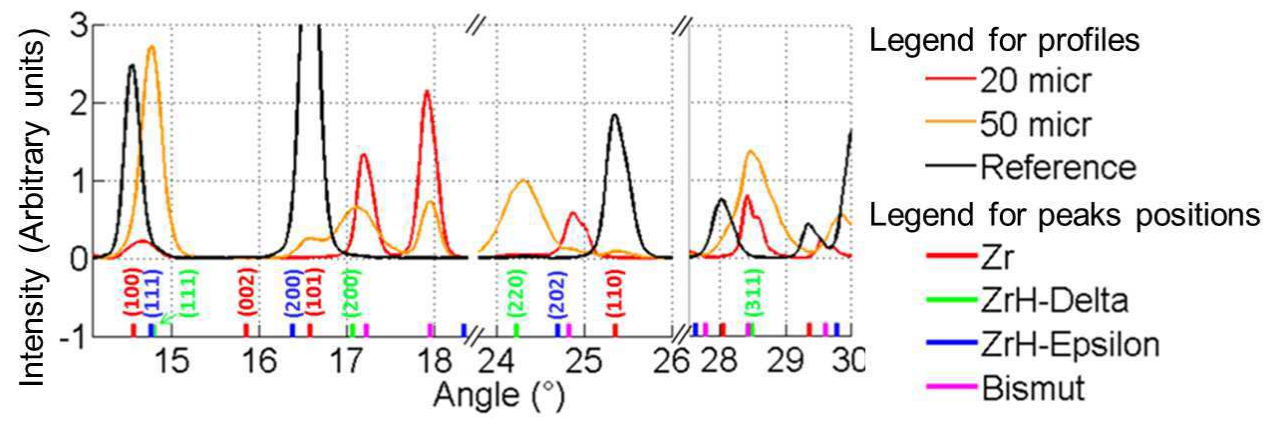

Figure 10: $\theta-2 \theta$ diagram obtained after integration on the whole angular sectors for a scan at $20 \mu \mathrm{m}$ and $50 \mu \mathrm{m}$ of the blister outer diameter (in red and orange respectively) and for a reference run on hydrided zirconium far from the blister (in black).

\subsubsection{Nano-hardness}

The two hardness distributions over a $217 \mu \mathrm{m}$ deep blister are constant throughout the hydrided matrix and increase at the matrix-blister interface until the 
middle of the blister depth, at which point they decrease (Figure 11(a)). To analyse this result, the evolution of the hardness of pure zirconium was plotted as a function of the hydrogen content based on results available in the litterature (Figure 11(b)). Interestingly, the hardness decreases sharpely from the boundary $\alpha+\delta \rightarrow \delta$ till reaching a plateau at the $\delta \rightarrow \delta+\varepsilon$ boundary. Thus, the decrease observed in the nanohardness measurements is likely due to the complete transformation $\alpha+\delta \rightarrow \delta$, in agreement with the ERDA and XRD measurements. The elastic modulus begins to decrease at the matrix-blister interface, for a reason that has not yet been identified, and then decreases even more rapidly at the same location where the hardness decreases (Figure 11(c)). This is consistent with the decrease of the elastic modulus in the $\delta$-hydride domain reported in the literature (Figure 11(d)). No sharp elastic modulus increase is observed at the matrix blister interface. This indicates the elastic modulus value is similar for unhydrided and highly-hydrided zirconium until the $\alpha+\delta \rightarrow \delta$ transition, thus supporting the elasticity modulus reported by Puls et al. [65] but not the one of Yamanaka et al. [31].

\section{Discussion}

\subsection{Comparison of different laboratory grown blisters}

Protrusion height to blister depth ratio. The protrusion height to blister depth ratio is $22 \%$ in the present study, while it is between $10 \%$ and $12.5 \%$ in blisters obtained by thermo-diffusion in $\mathrm{Zr}-2.5 \% \mathrm{Nb}[5,8,9]$, and $15 \%$ in blisters obtained in Zircaloy- 4 samples by local acceleration of hydrogen uptake by Glendening [2]. The discrepancy between the $22 \%$ ratio in the present study and the $15 \%$ ratio in Glendening [2] is not clearly identified but could be due to lower hydrogen content in the core of the blisters obtained by a locally accelerated hydrogen uptake process. The reason of the discrepancy between the ratio in Zircaloy-4 blister from our study and $\mathrm{Zr}-2.5 \% \mathrm{Nb}$ is not due (at least not completely) to a very low hydrogen content in Zr-2.5\% blisters. XRD experiments showed that the hydrogen content in the core of a Domizzi et al. [7] blister is of about $80 \%$ in volumetric fraction [75] .

We propose a hypothesis to justify the discrepancy in protusion height to depth ratio that relies on three items. First, the crystallographic 


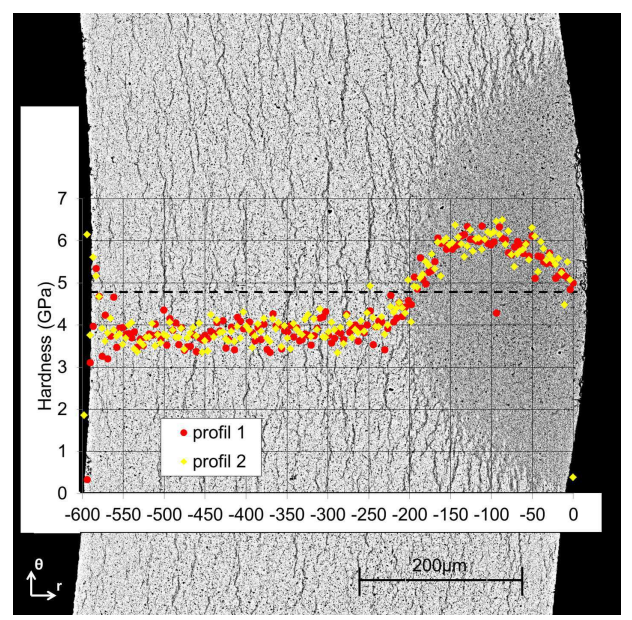

(a)

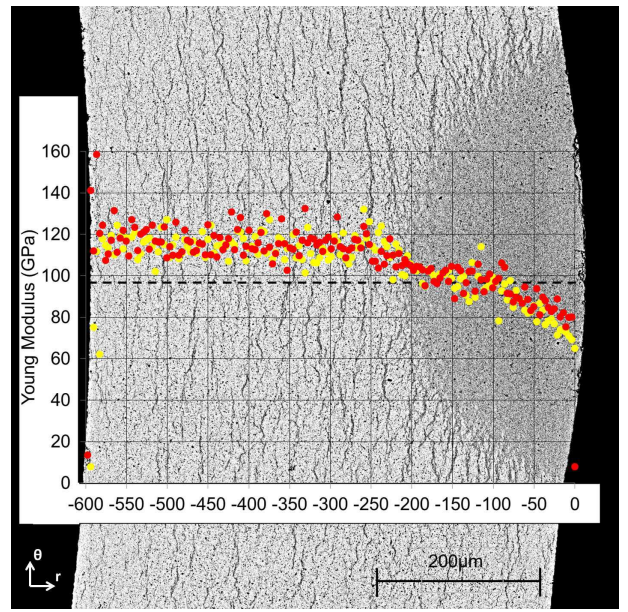

(c)

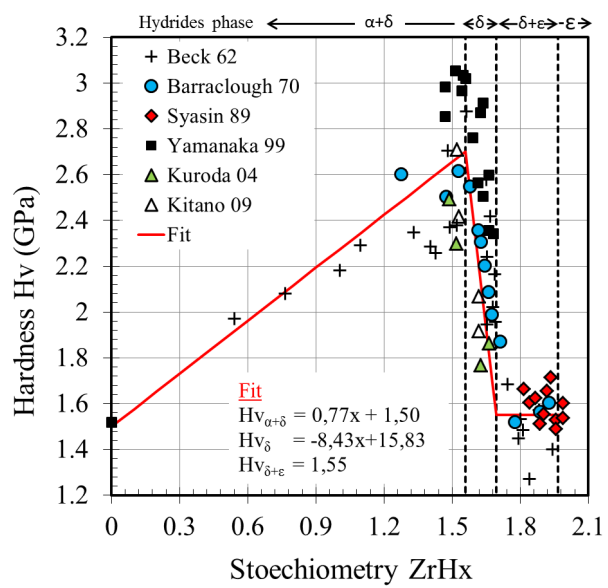

(b)

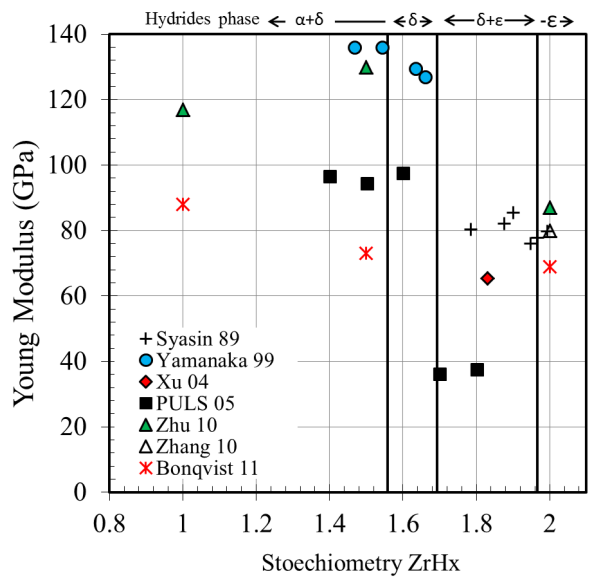

(d)

Figure 11: (a) Nanohardness measurements with a 10mN load on two profiles on a $217 \mu \mathrm{m}$ deep blister on the radial circumferential plane, (b) evolution of the hardness of the hydrided zirconium as a function of the hydrogen content from [31, 66, 67, 68, 69, 70], (c) elastic modulus measured from the nanohardness measurements considering a $\nu=0.3$ Poisson ratio and (d) evolution of the elastic modulus of the hydrided zirconium as a function of the hydrogen content from $[31,65,68,71,72,73,74]$. 
texture of the Zr-2.5\% Nb tubes $(<c>$ axes close to the circumferential direction) is different from the one of Zircaloy-4 cladding tubes $(<c\rangle$ axes on the radial-circumferential plane at $\pm 30^{\circ}$ to the radial direction). Secondly, Vicente-Alvarez et al. [75] XRD experiments showed that the relationship between the zirconium matrix and the microscopic $\delta$-hydrides platelets $(0001)_{Z r} / /(111)_{\delta}$ and $[11 \overline{2} 0]_{Z r} / /[1 \overline{1} 0]_{\delta}$ was maintained for the blister in $\mathrm{Zr}-2.5 \mathrm{wt} \% \mathrm{Nb}$, which could be the case for Zircaloy-4 too (this point needs confirmation). Thirdly, it was shown that expansion due to hydride precipitation is primarily accommodated in the direction normal to platelet thickness [62]. Therefore, blister growth might induce a higher protrusion but lower circumferential stresses for blisters grown in Zircaloy-4 cladding tubes compared to $\mathrm{Zr}-2.5 \% \mathrm{Nb}$ due to the different crystallographic textures.

Sunburst morphology. The sunburst pattern of radial hydrides beneath the blisters obtained by thermo-diffusion in the present study (Figure $12(\mathrm{a}))$ is similar to the ones observed in $\mathrm{Zr}-2.5 \% \mathrm{Nb}$ alloys with different textures $[5,6,10]$. The blister in Figure 12(b) obtained by locally accelerated hydrogen charging seems to have a less dense sunburst but consists of larger and longer radial hydrides.

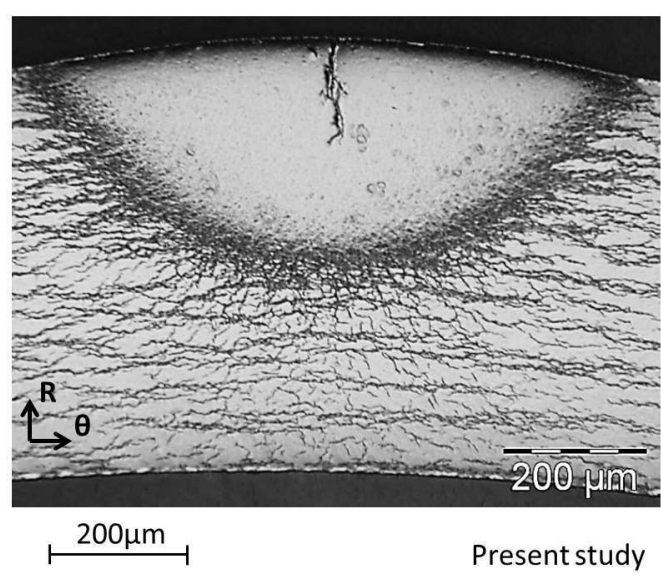

(a)

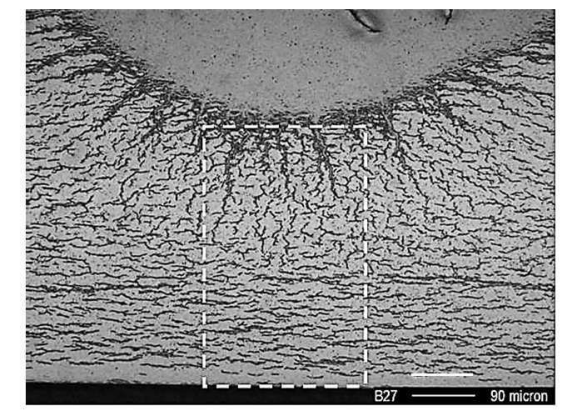

Raynaud 2007

(b)

Figure 12: Blister obtained in laboratory by thermo-diffusion in (a) the present study and by (b) Raynaud in [76] (courtesy of P. Raynaud from the U.S. Nuclear Regulatory Commission, USA). 
Cracks. All the blisters observed by SEM in the present study were cracked. This seems to be in contradiction with the compressive stress field that develops in the blister in the axial and circumferential directions during its growth, due to hydride precipitation-induced expansion [62, $77,78]$. It has been suggested by Wallace [79] that the cracking could occur during the blister growth due to the protrusion growth. Another likely assumption is that the blister cracking occurs during the cooling phase due to the difference in thermal expansion coefficients of the hydrides and the zirconium matrix. The $\delta$-hydride expansion coefficient is typically 2 times greater than that of zirconium in the $\langle c\rangle$ direction and 4 times higher in the $\langle a\rangle$ direction (using values from Yamanaka et al. [42] for $\delta$-hydrides and IAEA data [63] for zirconium).

No specific cracks spatial distribution was observed in the 12 samples analyzed with $60 \mu \mathrm{m}$ to $310 \mu \mathrm{m}$ deep blisters. Considering that the $\langle c\rangle$ axes fraction is slightly greater in the circumferential direction than in the axial direction, the differential expansion between the blister and the zirconium should be higher in the axial direction. This could have induced more circumferential cracks than axial cracks.

\subsection{Comparison of laboratory to reactor grown blisters}

Morphology. The blister microstructure is similar to the ones of Fuketa et al. [23] that have a 55\% depth to half diameter ratio, which is close to the $70 \%$ ratio of the present study. They also found a sunburst of radial hydrides beneath the blister. With the exception of the air jet blister generated by Leger [8], the thermo-diffusion grown blisters depth to half diameter ratio are all between $55 \%$ and $90 \%$ (Table 1). On the other hand, other reactor grown blisters observations reported in the litterature are flatter, such as the one observed by Bossis et al. [1] that has an approximately $20 \%$ depth to half diameter ratio.

Hardness. Fuketa et al. [23] measured the Vickers microhardness on the circumferential-radial plane of a $25.6 \mathrm{GWd} / \mathrm{tU}$ Zircaloy-4 cladding that was tested in the NSRR reactor. The hardness increases from $250 \mathrm{~kg} / \mathrm{mm}^{2}$ in the matrix beneath the blister to $450 \mathrm{~kg} / \mathrm{mm}^{2}$ in the blister. The irradiated Zircaloy-4 matrix hardness is higher than the unirradiated one. Some Vickers indents performed in the present study on the radial-circumferential plane of unirradiated Zircaloy-4 samples 
were constant for $100 \mathrm{~g}, 200 \mathrm{~g}$ and $300 \mathrm{~g}$ load and equal to $226 \pm 3$ $\mathrm{kg} / \mathrm{mm}^{2}$. The $200 \mathrm{~kg} / \mathrm{mm}^{2}$ hardness increase between the irradiated matrix and the blister is high compared to literature data (the maximum increase is of about $150 \mathrm{~kg} / \mathrm{mm}^{2}$ based on the Figure 11(b)). This may indicate that the irradiation-induced hardening is higher in hydrides than in zirconium, but more measurements are required on irradiated materials to draw a clear conclusion.

Hydrogen content in the blister. The only hydrogen quantification of a blister formed in an irradiated cladding tube is the one published by Laursen et al. [80]. They measured the hydrogen content by Nuclear Reaction Analysis on a blister formed in a Zircaloy-2 pressure tube that had been in service for 13 years. The blister reached $2.9 \pm 0.4 \mathrm{wt} \%$ in deuterium content close to the external surface, which is a bit less than the $\alpha+\delta \rightarrow \delta$ transition point at $25^{\circ} \mathrm{C}$, which is equal to $3.4 \mathrm{wt} \%$ (based on Thermo-Calc software calculations [61] and converting the hydrogen to deuterium limit by multiplying by two). The thermal conditions to obtain such a blister are nevertheless not representative of PWR conditions, which might result in different hydrogen distributions.

Blister growth rate in reactor conditions. The temperature across the thickness of a Zircaloy-4 cladding tube depends on the axial position and on the linear power. Considering a linear power of $155 \mathrm{~kW} / \mathrm{m}$, the outer cladding temperature at span 5 is approximately $325^{\circ} \mathrm{C}$, and the temperature is $346^{\circ} \mathrm{C}$ on the inner diameter $\left(21^{\circ} \mathrm{C}\right.$ temperature difference through the thickness). Considering that the presence of a $100 \mu \mathrm{m}$ oxide layer does not affect the external temperature (interface oxyde/water) but only the inner temperature (interface cladding-fuel pellet), the inner temperature reaches $372{ }^{\circ} \mathrm{C}$ for a $100 \mu \mathrm{m}$ thick oxide. When the zirconia is spalled, one can assume that the outer temperature (interface cladding - water at the spalled location) remains identical to the one before oxide spalling $\left(325^{\circ} \mathrm{C}\right)$. Therefore, the through thickness temperature difference leading to hydride blisters in reactor conditions can be assumed to be approximatively $372^{\circ} \mathrm{C}$ to $325^{\circ} \mathrm{C}$. Figure 6(c) indicates that the blister growth rate under these conditions is only 1.5 times slower than the one obtained in the present study. Thus, a half cladding deep blister growth in PWR conditions would only require about 1 to 2 days. 


\subsection{Impact of the blister-induced stress field on the hydrogen thermo-diffusion}

During the blister growth, the blister core is subjected to compressive stresses and the bulk beneath the blister is subjected to tensile stresses. Stress gradients induce hydrogen diffusion was observed in various studies about hydrogen induced delayed hydride cracking [81] and in a study of Kammenzind et al. [82]. Hydrogen diffusion in a thermal, a hydrogen concentration gradient and a stress gradient can be modelled in the framework of the thermodynamic of the irreversible processes by the equation 2 plus a term for the stress gradient contribution [81]:

$$
J=-D \frac{d C}{d x}-\frac{D C Q^{*}}{R T^{2}} \frac{d T}{d x}+D \frac{C \bar{V}}{R T} \frac{\partial P}{\partial x}
$$

with $\bar{V}$ the hydrogen partial molar volume in zirconium and $P$ the hydrostatic

pressure equal to $\frac{\operatorname{tr}(\sigma)}{3}$. Thus, the ratio of the stress gradient contribution to the thermal gradient contribution is defined by :

$$
\text { Ratio }=\frac{\overline{\frac{V}{3}} \frac{\partial s i g m a}{\partial x}}{\frac{Q^{*}}{T} \frac{d T}{d x}}
$$

To have a similar contribution of the stress gradient and the thermal gradient on hydrogen diffusion, that is Ratio $=1$, it requires :

$$
\frac{\frac{\partial \operatorname{sigma}}{\partial x}}{\frac{d T}{d x}}=\frac{3 Q^{*}}{\bar{V} T}
$$

The numerical application of equation 13, using $Q^{*}=25 \mathrm{~kJ} / \mathrm{mol}$ (Table 2) and $\bar{V}=1.67 \mathrm{~cm}^{3} / \mathrm{mol}[83]$, is displayed in Figure 13 . At $375^{\circ} \mathrm{C}$, a $681 \mathrm{MPa} / \mathrm{m}$ stress gradient is equivalent to a $10^{\circ} \mathrm{C} / \mathrm{m}$ thermal gradient in terms of the contribution on hydrogen diffusion.

The tensile stress field beneath a blister, during the blister growth, was calculated by finite differences calculations in [79, 84], and with the Eshelby inclusion theory [85] by Singh et al. [86]. Santisteban et al. [87] measured the residual stress field beneath a blister formed by Domizzi et al. [6] in a Zr$2.5 \% \mathrm{Nb}$ cladding tube by synchrotron XRD. This measured stress field is not representative of those during the blister growth, as XRD measurements were performed at $25^{\circ} \mathrm{C}$. Overall, the local thermal or stress gradient right beneath 


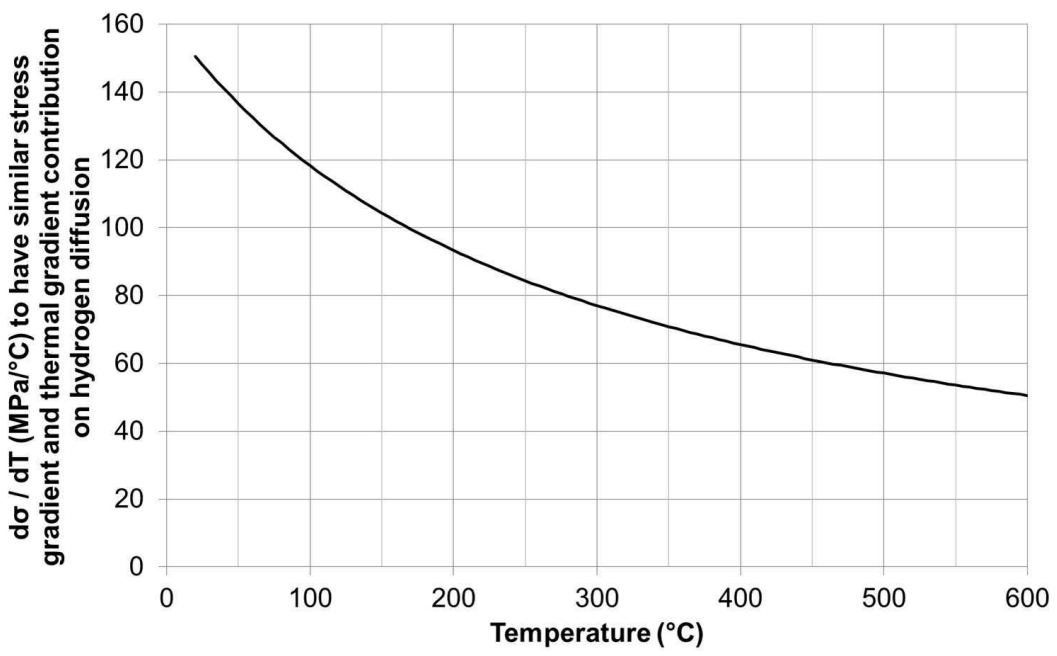

Figure 13: Stress to the thermal gradient ratio so their contribution to hydrogen diffusion is quantitatively identical

the blister is not precisely known. Between $1 \mathrm{~mm}$ and $2 \mathrm{~mm}$ of the blistermatrix interface, Singh et al. [86] estimated the stress gradient in the bulk is $50 \mathrm{MPa} / \mathrm{mm}$, while the thermal gradient in the present study between 1 and $2 \mathrm{~mm}$ was about $8^{\circ} \mathrm{C} / \mathrm{mm}$. Based on the equation 13 , the stress gradient contribution is about 10 times lower than the thermal gradient one. Thus, the stress gradient contribution to the blister growth kinetic is negligible compared to the thermal gradient one, based on the actual knowledge of the stress and temperature distributions beneath a blister during it growth.

\subsection{What does limit the blister growth?}

The simulation of Sawatzky [35] and Kammenzind et al. [34] thermo-diffusion experiments did not clarify whether one or two solubility limits should be considered to model hydrogen thermo-diffusion for a time independent thermal gradient. On the other hand, hysteresis in the solubility limit was observed in DHC experiments [46] and in blister growth experiments under thermal cycling [88]. Therefore, the hysteresis might also play a role in hydrogen diffusion.

When considering the one solubility limit model, the only limit to prevent 
hydride blister growth is that the hydrogen content should remain below the Blister Formation Threshold (BFT) $[10,88]$. The BFT is a condition on the initial hydrogen content for a given thermal gradient. It is expressed using the hydrogen in solid solution concentration at equilibrium in a linear thermal gradient (when the hydrogen flux $J$ is null), given by the following equation (refer to $[10,88]$ for details):

$$
C(x)=T S S\left(T_{C s}\right) e^{\frac{Q^{*}}{R} \frac{T_{C s}-T(x)}{T_{C s} T(x)}}
$$

The BFT is then defined by:

$$
\mathrm{BFT}=\int^{x} C(x) d x
$$

where $C(x)$ is the hydrogen in solid solution distribution, $T S S$ corresponds to the $T S S P$ if the hysteresis in the hydrogen solubility limit is considered, and $T_{C s}, Q^{*}$ and $R$ are the temperature at cold spot, the heat of transport, and the gas constant. The BFT is equal to $160 \mathrm{wppm}$ for a $325^{\circ} \mathrm{C}$ to $372^{\circ} \mathrm{C}$ temperature difference (linear thermal gradient) described above for a spalled cladding at fifth span from the rod bottom. For comparison, the hydrogen content can reach 700 wppm on average in highly irradiated claddings [89]. Even if the hydrides are not homogeneously distributed, with a rim structure, blister growth would not be limited if only one hydrogen solubility limit is considered.

Another blister growth limit should be considered if both the TSSD and TSSP are taken into account, in addition to the BFT. The second limit is when the hydrogen distribution, reached at equilibrium, is such that the hydrogen content is equal to the TSSP at the cold spot and equal to the TSSD at the hot side (Figure 14(a)). This situation will be referred to as "Diffusion Equilibrium Threshold (DET)" in the present article. The DET does not depend on the total hydrogen content if the total hydrogen content is higher than the concentration in solid solution. That means it is possible to reach a hydrogen diffusion equilibrium while precipitated hydrides are still available everywhere in the bulk. The DET situation can be described by equating the TSSD at the hot side (at bulk temperature $T_{b}$ ) to the hydrogen in solid solution concentration at the hot side calculated with the BFT resulting 
hydrogen distribution

$$
\left\{\begin{aligned}
T S S D_{b} & =T S S P_{C s} e^{\frac{Q^{*}}{R} \frac{T_{C s}-T_{b}}{T_{C s} T_{b}}} \\
C_{T S S D} e^{-\frac{Q_{C-T S S D}}{R T_{b}}} & =C_{T S S P} e^{-\frac{Q_{C-T S S P}}{R T_{C s}} e^{\frac{Q^{*}}{R} \frac{T_{C s}-T_{b}}{T_{C s} T_{b}}}} \\
T_{C s} & =T_{b}\left(\frac{Q_{C-T S S P}+Q^{*}}{R T_{b} \ln \left(C_{T S S P} / C_{T S S D}\right)+Q_{C-T S S D}+Q^{*}}\right)
\end{aligned}\right.
$$

with $T S S D=C_{T S S D} e^{-\frac{Q_{C-T S S D}}{R T}}$ in wppm and $T S S P=C_{T S S P} e^{-\frac{Q_{C-T S S P}}{R T}}$ in wppm.

Pan et al. [90] reported two TSSP solvus, named TSSP1 and TSSP2. The TSSP1, which is the commonly reported TSSP by Diferential Scanning Calorimetry, corresponds to the precipitation solvus when no precipitated hydrides are present in the material (nucleation of the first hydrides). The TSSP2 corresponds to the precipitation solvus with already precipited hydrides or with a memory effect when larged precipitated hydrides had already formed in the material and that the annealing temperature was not high enough to remove the induced dislocations [91]. Thus TSSP2 is also referred to as "growth solvus".

The temperatures to apply at the cold side $T_{\text {cold }}$ for a given temperature at the hot side $T_{H o t}$ were first calculated using the equation (16) considering the TSSD and TSSP reported by Kammenzind et al. [34] (Figure 14(b)). The technique used to determine such TSSP was to apply a thermal gradient on an homogeneously hydrided specimen, and then to measure the hydrogen concentration distribution. This technique allows to identify the TSSP1.

The DET was then calculated again using Tang and Yang [92] reported TSSD and TSSP. The TSSD is defined by TSSD $=52575 \exp (-32117 / \mathrm{RT})$ and the TSSP is defined by TSSP $=40135 \exp (-27336 / \mathrm{RT})$, both in wppm. Tang and Yang [92] performed Differential Scanning Calorimetry (DSC) to measure such TSSD and TSSP, with a $500{ }^{\circ} \mathrm{C}$ peak temperature on sample hydrided up to $240 \mathrm{wppm}$. Such $500^{\circ} \mathrm{C}$ peak temperature is much higher than $370^{\circ} \mathrm{C}$, the temperature associated with a TSSP equal to $240 \mathrm{wppm}$. As a consequence, the TSSP measured by Tang and Yang [92] corresponds to the TSSP1.

The DET calculated with Kammenzind et al. [34] or Tang and Yang [92] TSSD and TSSP are similar in absolute value, within 30 to $40^{\circ} \mathrm{C}$ for a hot 
side temperature between 150 and $450{ }^{\circ} \mathrm{C}$.

The DET was then calculated again, using the TSSD and TSSP reported by Mc Minn et al. [93] (Figure 14(b)). Differential scanning calorimetry was used to determine theses two solvus, with a peak temperature only $30^{\circ} \mathrm{C}$ higher than the TSSP without any hold period. Mc Minn et al. [93] performed additional tests at higher peak temperature and/or with hold period that showed the TSSP firstly identified can be considered as being the TSSP2. The TSSD is equal to TSSD $=106447 \exp (-35989 / \mathrm{RT})$ and the TSSP2 is equal to TSSP2 $=138746 \exp (-34468 / \mathrm{RT})$. The DET absolute value are lower than the ones calculated with Kammenzind et al. [34] and Tang and Yang [92] data (Figure 14(b)). Thus the experimental determination of the DET would be an interesting experiment to discriminate between the different solubility limits identified in the litterature.

Additionally, several studies showed the hydrogen solubility and the heat of transport are affected by neutron irradiation. This might modify the DET determined above for unirradiated claddings.

Regarding the effect of the irradiated state of the cladding tube on the hydrogen solubity limit, Mc Minn et al. [93] showed that the TSSP2 is increased and the TSSD too, on irradiated Zircaloy-2 and Zircaloy-4 up to fluence $5.5 \times 10^{20}$ to $1.0 \times 10^{22}(\mathrm{E}>1 \mathrm{MeV})$ compared to unirradiated material. This was confirmed in irradiated Zircaloy-4 measuring only the TSSD [94, 95, 96]. A physical explanation for this increase can be the locking of hydrogen atoms on point defects that reduces the effective solubility limit. This is in agreement with the ab initio calculations of Iwasawa et al. [97], their study is concluded by "In the presence of a $\mathrm{Zr}$ vacancy, hydrogen can easily be located around the Zr vacancy and move toward the Zr vacancy, but cannot easily move far from the Zr vacancy.". In addition, deuterium trapping was observed in ion-irradiated Zr [98]. The increase in the TSSD and TSSP may also be explained by the irradiation hardening of the matrix [46, 93]. Puls' [46] theoretical prediction is that the TSSD would be slightly shifted and the TSSP largely shifted to higher content. On the other hand, the effect of neutron irradiation on the hydrogen solubility limit in zirconium alloys is still a matter of controversy since Une et al. [99] did not observed an irradiation effect on the solubility limit on irradiated Zircaloy-2 at $5.4-12.9 \times 10^{25} \mathrm{n} / \mathrm{m}^{2}$.

Regarding the effect of the irradiated state of the cladding tube on the heat of transport, the only study to the authors knowledge that reports experimental results is the one of Sasahara et al. [96]. The $\mathrm{Q}^{*}$ increase from $18.8-29.7 \mathrm{~kJ} / \mathrm{mol}$ on unirradiated material to $44.3-74.0 \mathrm{~kJ} / \mathrm{mol}$ on 58 
$\mathrm{GWd} / \mathrm{tU}$ irradiated cladding ( $+244 \%$ increase in average).

Thus, the temperature difference to reach the DET was calculated again for irradiated material, taking into account the evolution of the solubility limit according to Mc Minn et al. [93] (TSSD $-21.7 \%$ on the activation energy and $-77.2 \%$ on the prexponential factor and TSSP $2-14.2 \%$ on the activation energy and $-52.2 \%$ on the prexponential factor) and of the heat of transport according to Sasahara et al. [96] $\left(\mathrm{Q}^{*}=25 \mathrm{~kJ} / \mathrm{mol}\right.$ to $\left.66 \mathrm{~kJ} / \mathrm{mol}\right)$. Considering material irradiation has a low impact on the DET (Figure 14(b)). Hydride blisters could grow with a hot side temperature equal to $375^{\circ} \mathrm{C}$ if the linear temperature difference is higher than $31^{\circ} \mathrm{C}$ based on Mc Minn et al. [93] on unirradiated material and $28^{\circ} \mathrm{C}$ based on Mc Minn et al. [93] on irradiated material.

This analysis on the DET is supported by the thermo-diffusion results reported by Garzarolli et al. [100]. Their experiment consisted of applying a linear thermal gradient across the thickness of pre-hydrided cladding specimens. The temperature range was $260^{\circ} \mathrm{C}$ to $490^{\circ} \mathrm{C}$. Figure 15 is a reinterpretation of their results. The initially reported heat flux abscissa was converted into temperature difference thanks to the limited variation of the thermal conductivity on the $260-490{ }^{\circ} \mathrm{C}$ temperature range (15 to 17.6 W/(K.m) based on IAEA [101]). The BFT and DET were calculated with the solubility limits of Kammenzind et al. [34] for the TSSP1 and of Mc Minn et al. [93] for the TSSP2. The BFT is similar when calculated with the TSSP1 or the TSSP2, but it depends on the bulk temperature. The BFT limit explains the circle points at $10^{\circ} \mathrm{C}-217 \mathrm{wppm}$ and $18^{\circ} \mathrm{C}-242 \mathrm{wppm}$, and the three triangles below $400 \mathrm{wppm}$ that could be samples in which limited hydrogen diffusion allowed the BFT to be reached. The DET depends on both the solubility limit (TSSP1 or TSSP2) and of the temperature. The DET temperature dependance depends on the solubility model used, as illustrated in Figure 14. The effective DET measured by Garzarolli et al. [100] should be between the two red triangles at about $20^{\circ} \mathrm{C}$ and $650-700 \mathrm{wppm}$, which is not excessively far from the DET theoretical predictions.

\section{Conclusion}

A setup was developed to grow blisters on Zircaloy-4 PWR cladding tubes in optimized conditions defined with thermo-diffusion calculations. Blisters typically reached $290 \mu \mathrm{m}$ in depth after $24 \mathrm{~h}$. The blisters obtained in the present 


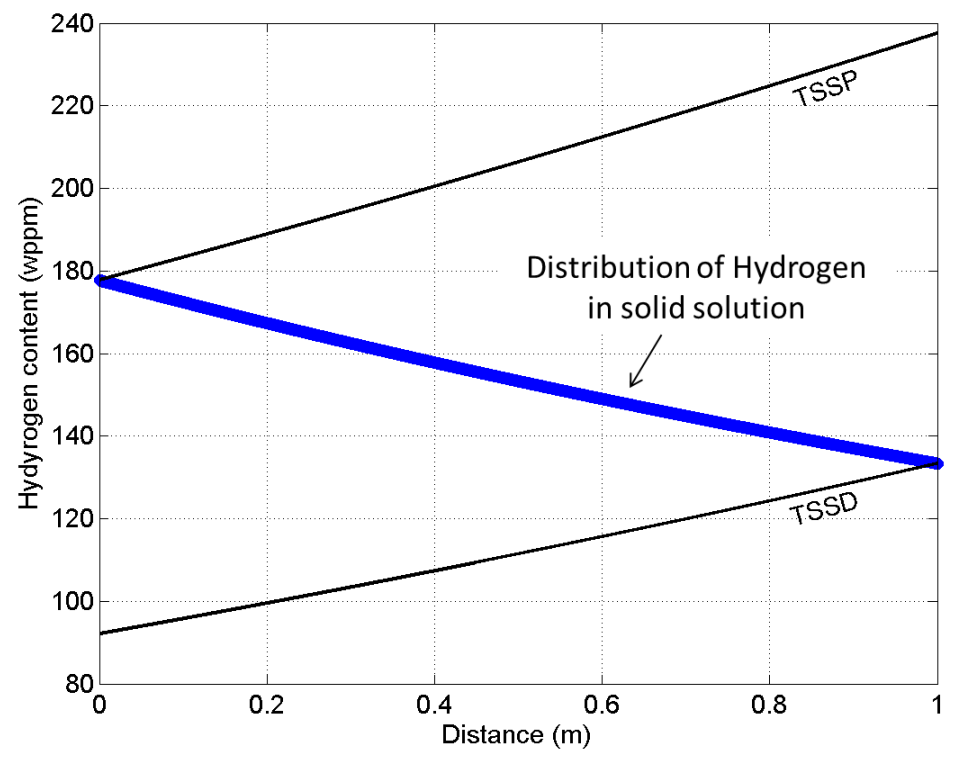

(a)

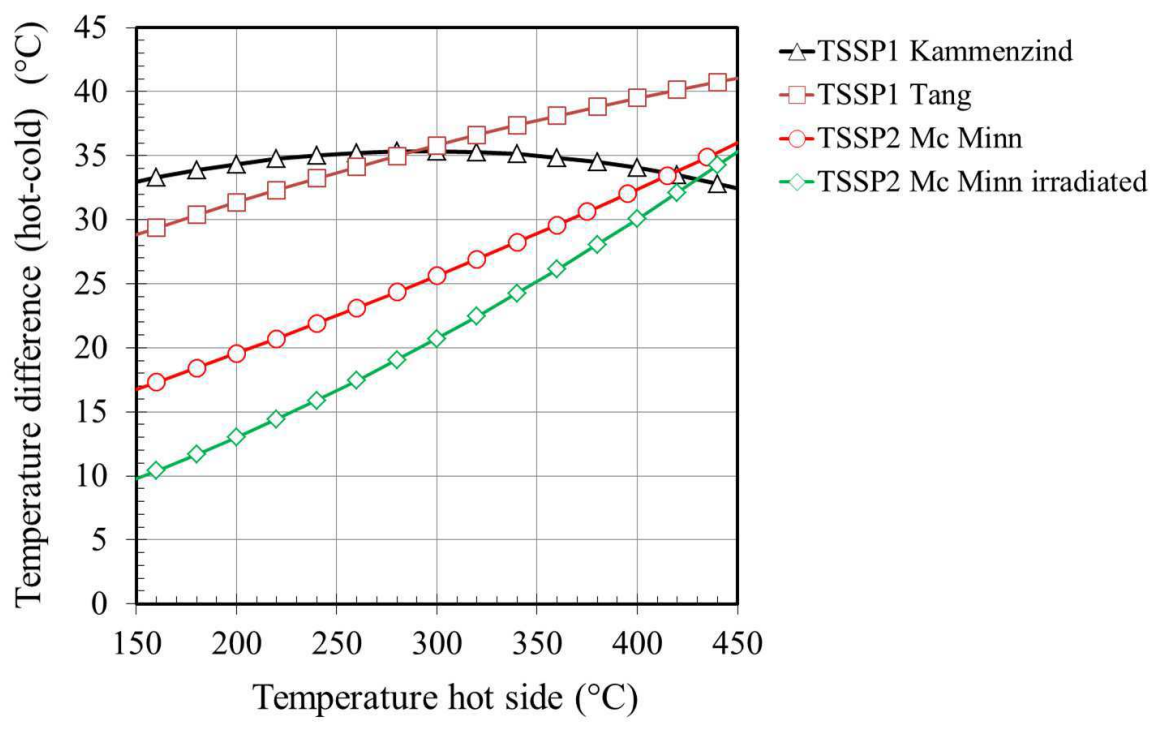

(b)

Figure 14: (a) Hydrogen concentration in solid solution at DET reached assuming two solubility limits (the metric unit are arbitrary) and (b) temperature difference to reach the DET as a function of temperature on the hot side, considering the TSSP1 or TSSP2. 


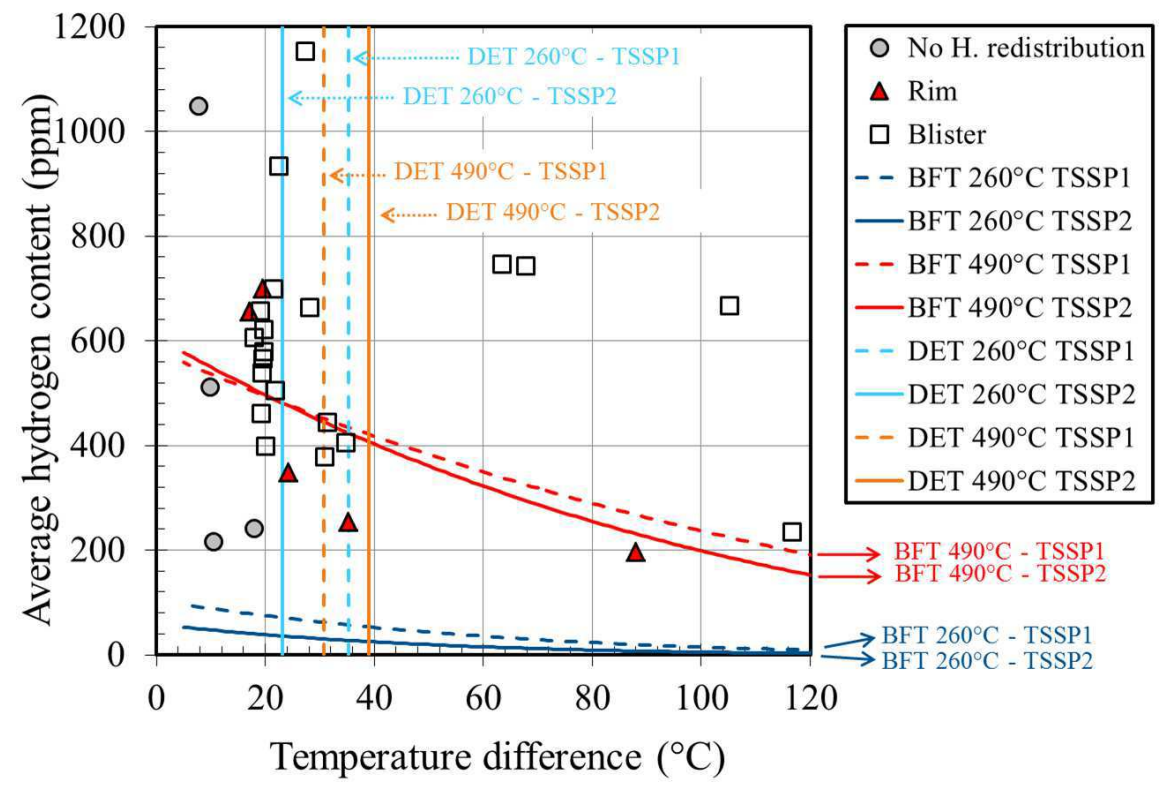

Figure 15: Reinterpretation of the hydrogen microstructure reported by Garzarolli et al. [100] after thermo-diffusion tests in the cladding thickness. 
study are representative of laboratory-induced blisters obtained in previous studies and of some blisters observed in spent fuel Zircaloy-4 claddings after reactor exposure. ERDA, XRD and nano-hardness showed the blisters contain a hydrogen gradient, with pure $\delta$-hydride phase close to the external surface over one third of the blister depth. thermo-diffusion calculations showed these half thickness blisters should grow in only few days in PWR conditions. Eventually, the Diffusion Equilibrium Threshold (DET) was defined as a criterion that limit the blister growth, and emphasized that the hysteresis in the hydrogen solubility limit in zirconium must be taken into account to model hydrogen thermo-diffusion in zirconium alloys.

\section{Acknowledgements}

The anonymous reviewer contribution to this paper is greatly acknowledged. We are grateful to Martine Blat, Friedrich Garzarolli, Arthur Motta for the information provided, Pattrick Raynaud and Toyoshi Fuketa for the two blister pictures used in this article. This work involved several persons from the CEA: Stephane Allègre, Marie Azera, Luc Belin, Pierre Billaud, Patrick Bonnaillie, Matthew Bono, Phillipe Bossis, Annick Bougault, Jean-Christophe Brachet, Clara Desgranges, Pierre Forget, Pierre Gavoille, David Leboulch, Caroline Mallet, Denis Menut, Philippe Mongabure, Olivier Rabouille, Elodie Rouesne, Caroline Toffolon and Marc Tupin. Xavier Averty and Christophe Poussard support to this study is acknowledged.

\section{References}

[1] P. Bossis, D. Pecheur, K. Hanifi, J. Thomazet, M. Blat, Comparison of the high burn-up corrosion on $\mathrm{M} 5{ }^{\circledR}$ and low tin Zircaloy-4, in: B. Kammenzind, P. Rudling (Eds.), 14th International Symposium on Zirconium in the Nuclear Industry, Vol. 3, ASTM STP 1467, Stockholm, Sweden, (2005), pp. 494-525.

[2] A. Glendening, Influence of hydride blisters on the failure of Zircaloy-4 under equal biaxial tension, Ph.d. thesis, Penn State University (2004). 
[3] A. White, A. Sawatzky, C. Woo, A computer model for hydride-blister growth in zirconium alloys, Tech. Rep. Report AECL-8386, Atomic Energy of Canada Limited (1985).

[4] G. Field, J. Dunn, B. Cheadle, An Analysis of the Pressure Tube Rupture at Pickering NGS "A" Unit 2, Canadian Metallurgical Quarterly 24 (3) (1985) pp. 181-188.

[5] M. Puls, Determination of fracture initiation in hydride blisters using acoustic emission, Metallurgical Transactions A 19A (1988) pp. 22472257.

[6] G. Domizzi, R. Enrique, J. Ovejero-Garcia, G. Buscaglia, Blister growth in zirconium alloys: experimentation and modeling, Journal of Nuclear Materials 229 (1996) pp. 36-47.

[7] G. Domizzi, G. Vigna, S. Bermdez, J. Ovejero-Garcia, Hydride distribution around a blister in Zr-2.5Nb pressure tubes, Journal of Nuclear Materials 275 (1999) pp. 255-267.

[8] M. Leger, G. Moan, A. Wallace, N. Watson, Growth, fracture and non destructive evaluation of hydride blisters in $\mathrm{Zr}-2.5 \mathrm{Nb}$ pressure tubes, in: P. Swam, C. Eucken (Eds.), 8th International Symposium on Zirconium in the Nuclear Industry, ASTM STP 1023, San Diego, USA, (1988), pp. $50-65$.

[9] Y. Cheong, U. Gong, K. Choo, S. Kim, Y. Kim, Formation and Growth of hydride blisters in Zr-2.5Nb Pressure tubes, Journal of the Korean Nuclear Society 33 (2) (2001) pp. 192-200.

[10] R. Singh, R. Kishore, T. Sinha, B. Kashyap, Hydride blister formation in Zr-2.5Nb pressure tube alloy, Journal of Nuclear Materials 301 (2002) pp. 153-164.

[11] M. Balourdet, C. Bernaudat, V. Basini, N. Hourdequin, The PROMETRA programme: Assessment of mechanical properties of Zircaloy-4 fuel cladding during an RIA, in: S. Pil Chang (Ed.), 15th International Conference on Structural Mechanics in Reactor Technology, Korean Nuclear Society, Seoul, Korea, (1999), pp. 485-492. 
[12] T. Fuketa, H. Sasajima, Y. Mori, K. Ishijima, Fuel failure and fission gas release in high burnup PWR fuels under RIA conditions, Journal of Nuclear Materials 248 (1997) pp. 249-256.

[13] A. Garde, G. Smith, R. Pirek, Effects of hydride precipitate localization and neutron fluence on the ductility of irradiated Zircaloy4, in: E. Bradley, G. Sabol (Eds.), 11th International Symposium on Zirconium in the Nuclear Industry, ASTM STP 1295, GarmischPartenkirchen, Germany, (1996), pp. 407-430.

[14] M. Blat-Yrieix, A. Ambard, C. Watroba, A. Miquet, A. Legris, Poster: How to obtain in laboratory representative hydride blisters on zirconium alloys: A survey of surface effect, in: M. Limback, B. Barberis (Eds.), 16th International Symposium on Zirconium in the Nuclear Industry, ASTM STP 1529, Chengdu, China, (2010).

[15] P. Guedeney, M. Trotabas, Caracterisation du comportement du combustible Fragema fort taux de combustion, in: International Topical Meeting on Light Water Reactor Fuel Performance, Avignon, France, (1991).

[16] R. O. Meyer, R. K. McCardell, H. M. Chung, D. J. Diamond, H. H. Scott, A regulatory assessment of test data for reactivity initiated accidents, Nuclear Safety 37 (4) (1996) pp. 872-387.

[17] J. Papin, B. Cazalis, J. Frizonnet, E. Federici, F. Lemoine, Synthesis of CABRI-RIA tests interpretation, in: Eurosafe Meeting, Paris, France, (2003).

[18] J. Desquines, B. Cazalis, C. Bernaudat, C. Poussard, X. Averty, P. Yvon, Mechanical properties of Zircaloy-4 PWR fuel cladding with burnup 54-64MWd/kgU and implications for RIA behavior, in: B. Kammenzind, P. Rudling (Eds.), 14th International Symposium on Zirconium in the Nuclear Industry, Vol. 2, ASTM STP 1467, Stockholm, Sweden, (2005), pp. 851-872.

[19] A. Hermann, S. Yagnik, D. Gavillet, Effect of local hydride accumulations on Zircaloy cladding mechanical properties, in: M. Limback, B. F. Kammenzind (Eds.), 15th International Symposium on Zirconium in 
the Nuclear Industry, ASTM STP 1505, Sunriver, Oregon, (2007), pp. $141-162$.

[20] D. Bates, Influence of stress state and hydrogen on deformation and failure of Zircaloy-4, Master of science, Penn State University (1998).

[21] O. Pierron, D. Koss, A. Motta, K. Chan, The influence of hydride blisters on the fracture of Zircaloy-4, Journal of Nuclear Materials 322 (2003) pp. 21-35.

[22] P. Raynaud, D. Koss, A. Motta, K. Chan, Fracture toughness of hydrided Zircaloy-4 sheet under through-thickness crack growth conditions, Journal of ASTM international 5 (1) (2007) pp. 1-15.

[23] T. Fuketa, H. Sasajima, Y. Mori, K. Homma, S. Tanzawa, K. Ishijima, S. Kobayashi, H. Kamata, H. Sakai, Behavior of pre-irradiated fuel under a simulated RIA condition (Results of NSRR test JM-5), Tech. Rep. JAERI research 95-078, JAERI (1995).

[24] K. Murty, I. Charit, Texture development and anisotropic deformation of Zircaloys, Progress in Nuclear Energy 48 (2006) pp. 325-359.

[25] J. Dunlop, Y. Brechet, L. Legras, H. Zurob, Modelling isothermal and non-isothermal recrystallisation kinetics: Application to Zircaloy4, Journal of Nuclear Materials 366 (1-2) (2007) pp. 178-186.

[26] S. Allegre, L. Sachot, O. Rabouille, Method of analysing an image of hydrides in a metal alloy, notably in a nuclear fuel cladding alloy, us patent 2011/0116680 a1 (2011).

[27] C. Raepsaet, P. Bossis, D. Hamon, J. Bechade, J. Brachet, Quantification and local distribution of hydrogen within Zircaloy-4 PWR nuclear fuel cladding tubes at the nuclear microprobe of the Pierre Sue Laboratory from l-ERDA, Nuclear Instruments and Methods in Physics Research B (266) (2008) pp. 2424-2428.

[28] M. Mayer, SIMNRA, a simulation program for the analysis of NRA, RBS and ERDA, in: J. Duggan, I. Morgan (Eds.), 15th International Conference on the Application of Accelerators in Research and Industry, American Institute of Physics Conference Proceedings 475, Denton, Texas, USA, (1998), p. 541. 
[29] G. Plumereau, F. Ladieu, P. Berger, Noise-induced local heatings in microbeam analysis, Nuclear Instruments and Methods in Physics Research B 158 (1999) pp. 190-193.

[30] A. Hammersley, Fit2d : An introduction and overview., Tech. Rep. Internal Report ESRF97HA02T, European Synchrotron Radiation Facility (1997).

[31] S. Yamanaka, K. Yoshioka, M. Uno, M. Katsura, H. Anada, T. Matsuda, S. Kobayashi, Thermal and mechanical properties of zirconium hydride, Journal of Alloys and Compounds 293-295 (1999) pp. 23-29.

[32] A. W. Sommer, W. Dennison, Thermal diffusion of hydrogen in nonstoichiometric zirconium-dihydride., Tech. Rep. Technical Report NAASR-5066, Atomics International, Division of North American Aviation (1960).

[33] M. Gerl, Contribution l'etude theorique et experimentale de la thermodiffusion de defauts ponctuels dans les metaux, Ph.d. thesis, Faculte des sciences d'Orsay - Universite de Paris (1968).

[34] B. Kammenzind, D. Franklin, W. Duffin, H. Peters, Hydrogen pickup and redistribution in alpha-annealed Zircaloy-4, in: E. Bradley, G. Sabol (Eds.), 11th International Symposium on Zirconium in the Nuclear Industry, ASTM STP 1295, Garmisch-Partenkirchen, Germany, (1996), pp. 338-370.

[35] A. Sawatzky, Hydrogen in Zircaloy-2: Its distribution and heat of transport, Journal of Nuclear Materials 2 (4) (1960) pp. 321-328.

[36] J. Markowitz, The thermal diffusion of hydrogen in alpha-delta Zircaloy-2, Transactions of the Metallurgical Society of AIME 221 (1961) pp. 819-823.

[37] A. Sawatzky, The heat of transport of hydrogen in zirconium alloys, Journal of Nuclear Materials 9 (3) (1963) pp. 364.

[38] S. Morozumi, K. Kitada, K. Abe, S. Koda, Effects of alloying elements and cold work on the redistribution of hydrogen in zirconium under a temperature gradient, Journal of Nuclear Materials 33 (1969) pp. 261-270. 
[39] M. Sugisaki, Thermal diffusion of tritium and protium in alpha phase of zirconium,, Fusion Technology 14 (1988) pp. 723-728.

[40] K. Hashizume, M. Hayakawa, M. Koganemaru, M. Sugisaki, Temperature dependence of heat of transport of hydrogen in zirconium, Defect and Diffusion Forum 95 - 98 (1993) pp. 323-328.

[41] H. Hong, S. Kim, K. Lee, Thermotransport of hydrogen in Zircaloy-4 and modified Zircaloy-4, Journal of Nuclear Materials 257 (1) (1998) pp. $15-20$.

[42] S. Yamanaka, K. Yamada, K. Kurosaki, M. Uno, K. Takeda, H. Anada, T. Matsuda, S. Kobayashi, Thermal properties of zirconium hydride, Journal of Nuclear Materials 294 (1-2) (2001) pp. 94-98.

[43] J. Kearns, Dissolution kinetics of hydride platelets in Zircaloy-4, Journal of Nuclear Materials 27 (1968) pp. 64-72.

[44] O. Zanellato, M. Preuss, J. Buffiere, F. Ribeiro, A. Steuwer, J. Desquines, J. Andrieux, B. Krebs, Synchrotron diffraction study of dissolution and precipitation kinetics of hydrides in Zircaloy-4, Journal of Nuclear Materials 420 (2012) pp. 537-547.

[45] K. Une, S. Ishimoto, Dissolution and precipitation behavior of hydrides in Zircaloy-2 and high Fe Zircaloy, Journal of Nuclear Materials 322 (1) (2003) pp. 66-72.

[46] M. Puls, Review of the thermodynamic basis for models of delayed hydride cracking rate in zirconium alloys, Journal of Nuclear Materials 393 (2) (2009) pp. 350-367.

[47] G. Marino, A numerical calculation of the redistribution of an interstitial solute in a thermal gradient, Nuclear Science and Engineering 49 (1972) pp. 93-98.

[48] A. Sawatzky, The diffusion and solubility of hydrogen in the alpha phase of Zircaloy-2, Journal of Nuclear Materials 2 (1960) pp. 62-68.

[49] J. Kearns, Terminal solubility and partitioning of hydrogen in the alpha phase of zirconium, Zircaloy-2 and Zircaloy-4, Journal of Nuclear Materials 22 (3) (1967) pp. 292-303. 
[50] C. Korn, S. D. Goren, NMR study of hydrogen diffusion in zirconium hydride, Physical Review B 33 (1) (1986) pp. 68-78.

[51] C. Schwartz, M. Mallett, Observation of the behavior of hydrogen in zirconium, Transactions of the american society metals 46 (1954) pp. $641-654$.

[52] M. Mallet, W. Albrecht, Low pressure solubility and diffusion of hydrogen in zirconium, Journal of Electrochemical Society 104 (1957) pp. $142-146$.

[53] M. Someno, Determination of the solubility and diffusion coefficient of hydrogen in zirconium, Nihon Kinzoku Gakkaishi 24 (1960) pp. 249253.

[54] C. Cupp, P. Flubacher, An auto-radiographic technique for the study of tritum in metals and its application to diffusion in zirconium at $149 \mathrm{c}$ and 240c, Journal of Nuclear Materials 6 (1962) pp. 213-228.

[55] J. Kearns, Diffusion coefficient of hydrogen in alpha zirconium, Zircaloy-2 and Zircaloy-4, Journal of Nuclear Materials 43 (3) (1972) pp. 330-338.

[56] J. Austin, T. Elleman, K. Verghese, Tritium diffusion in Zircaloy-2 in the temperature range -78 to $204 \mathrm{C}$, Journal of Nuclear Materials 51 (1974) pp. 321-329.

[57] G. Greger, H. Munzel, W. Kunz, A. Schwierczinski, Diffusion of tritium in Zircaloy-2, Journal of Nuclear Materials 88 (1980) pp. 15-22.

[58] K. Hashizume, M. Sugisaki, K. Hatano, T. Ohmori, K. Ogi, Application of discharge implantation method to measurement of diffusion coefficient of hydrogen istopes in zirconium, Journal of Nuclear Science and Technology 31 (1994) pp. 1294-1300.

[59] C. Zhang, B. Li, P. Norton, The study of hydrogen segregation on $\operatorname{Zr}(0001)$ and $\operatorname{Zr}(1010)$ surfaces by static secondary ion mass spectroscopy, work function, Auger electron spectroscopy and nuclear reaction analysis, Journal of Alloys and Compounds 23 (1995) pp. 354-363. 
[60] D. Khatamian, Diffusion of deuterium in Zr-2.5Nb alloy under neutron irradiation, Journal of Alloys and Compounds 509 (2011) pp. S797S800.

[61] N. Dupin, I. Ansara, C. Servant, C. Toffolon, C. Lemaignan, J. Brachet, A thermodynamic database for zirconium alloys, Journal of Nuclear Materials 275 (1999) pp. 287-295.

[62] A. Hellouin de Menibus, T. Guilbert, Q. Auzoux, C. Toffolon, J. Bechade, J. Brachet, Hydrogen contribution to the thermal expansion of hydrided Zircaloy-4 cladding tubes, Journal of Nuclear Materials 440 (2013) pp. 169-177.

[63] IAEA, Thermophysical properties of materials for nuclear engineering: a tutorial and collection of data, IAEA, (2008).

[64] I. Ferguson, Computed X-Ray powder diffraction patterns and densities for corundum, aluminium, zirconium, delta-UZr2, and the zirconium hydrides, Tech. Rep. 2438, United Kingdom Atomic Energy Authority (1976).

[65] M. Puls, S.-Q. Shi, J. Rabier, Experimental studies of mechanical properties of solid zirconium hydrides, Journal of Nuclear Materials 336 (2005) pp. 73-80.

[66] R. Beck, Thermophysical properties of zirconium hydrides, American Society of Metals Transactions Quarterly 55 (1962) pp. 556-567.

[67] K. Barraclough, C. Beevers, Some observations on the phase transformations in zirconium hydrides, Journal of Nuclear Materials 34 (2) (1970) pp. 125-134.

[68] V. Syasin, E. Boyko, V. Markin, Investigations of hardness, internal friction and brittleness of zirconium hydride, Zeitschrift fur Physikalische Chemie Neue Folge 164 (2) (1989) pp. 1567-1572.

[69] M. Kuroda, D. Setoyama, M. Uno, S. Yamanaka, Nanoindentation studies of zirconium hydride, Journal of Alloys and Compounds 368 (2004) pp. 211-214. 
[70] Y. Kitano, K. Kurosaki, M. Ito, H. Muta, M. Uno, K. Konashi, S. Yamanaka, Fabrication and mechanical characterization of zirconium and gadolinium hydrides, Journal of Nuclear Materials 389 (1) (2009) pp. $170-172$.

[71] J. Xu, S. Shi, Investigation of mechanical properties of epsilonzirconium hydride using micro and nano-indentation techniques, Journal of Nuclear Materials 327 (2004) pp. 165-170.

[72] W. Zhu, R. Wang, G. Shu, P. Wu, H. Xiao, First principles study of different polymorphs of crystalline zirconium hydride, Journal of Physical Chemistry C 114 (50) (2010) pp. 22361-22368.

[73] P. Zhang, B. Wang, C. He, P. Zhang, First-principles study of ground state properties of zirconium dihydride, Computational materials science 50 (12) (2011) pp. 3297-3302.

[74] J. Blomqvist, J. Olofsson, A. Alvarez, C. Bjerken, Structure and thermodynamical properties of zirconium hydrides from first-principles, in: J. Busby, G. Llevbare, P. Andresen (Eds.), 15th International Conference Environmental Segradation of Materials in Nuclear Power Systems-Water Reactors, Colorado Springs, USA, (2011).

[75] M. Vicente-Alvarez, J. Santisteban, G. Domizzi, J. Almer, Phase and texture analysis of a hydride blister in a $\mathrm{Zr} 2.5 \mathrm{Nb}$ tube by synchrotron X-ray diffraction, Acta Materialia 59 (2011) pp. 2210-2220.

[76] P. Raynaud, Crack growth through the thickness of thin sheet hydrided Zircaloy-4, Ph.d. thesis, Penn State University (2009).

[77] G. Carpenter, The dilatation misfit of zirconium hydrides precipitated in zirconium, Journal of Nuclear Materials 48 (1973) pp. 264-266.

[78] V. Perovic, G. Weatherly, S. Mac Ewen, M. Leger, The influence of prior deformation on hydride precipitation in Zircaloy, Acta Metallurgica et Materialia 40 (2) (1992) pp. 363-372.

[79] A. Wallace, Numerical analysis of zirconium hydride blisters in CANDU reactor pressure tubes, in: A. B. Editors (Ed.), Ninth International conference on structural mechanics in reactor technology, Lausanne, Switzerland, (1987). 
[80] T. Laursen, M. Leger, M. Xin-Pei, J. Macarthur, G. Palmer, J. Whitton, The measurement of the deuterium concentration distributions in deuteride blisters on zirconium-alloy pressure tube material, Journal of Nuclear Materials 165 (2) (1989) pp. 156-163.

[81] D. Northwood, U. Kosasih, Hydrides and delayed hydrogen cracking in zirconium and its alloys, International Metals Reviews 28 (2) (1983) pp. $92-121$.

[82] B. F. Kammenzind, B. M. Berquist, R. Bajaj, P. H. Kreyns, D. G. Franklin, The long range migration of hydrogen through Zircaloy in response to tensile and compressive stress gradients, in: G. Sabol, G. Moan (Eds.), 12th international Symposium on Zirconium in the Nuclear Industry, ASTM STP 1354, Toronto, Canada, 1998, pp. 196233.

[83] S. R. MacEwen, C. E. Coleman, C. E. Ells, J. Faber Jr, Dilation of hcp zirconium by interstitial deuterium, Acta Metallurgica 33 (5) (1985) pp. 753757.

[84] M. Vanderglas, Y. Kim, Stresses due to volumetric expansion of zirconium hydride inclusions, International Journal of Pressure Vessels and Piping 22 (3) (1986) pp. 177-196.

[85] J. Eshelby, The elastic field outside an ellipsoidal inclusion, Proceedings of the Royal Society of London. Series A, Mathematical and Physical 252 (1271) (1959) pp. 561-569.

[86] R. Singh, R. Kishore, T. Sinha, S. Banerjee, B. Kashyap, Stress field estimation around a semi-constrained inclusion and its validation by interpreting hydride platelet orientation around a blister in a $\mathrm{Zr}-2.5 \mathrm{Nb}$ alloy, Materials Science and Engineering A339 (2003) pp. 17-28.

[87] J. Santisteban, A. Steuwer, G. Domizzi, M. Peel, Determination of residuals stresses around blisters in $\mathrm{Zr}-2.5 \mathrm{Nb}$ pressure tubes, Powder Diffraction 24 (2) (2009) pp. 572-576.

[88] M. Leger, M. Puls, T. Byrne, G. Moan, A. Causey, R. Klassen, M. Dolbey, E. Murphy, V. Urbanic, H. Wong, E. Price, N. Azer, D. Rodgers, The formation and characteristics of hydride blisters in cold worked 
Zircaloy-2 pressure tubes, in: E. Price (Ed.), IAEA Consultants' Meeting, E.G. Price, Vienna, Austria, (1994).

[89] A. Machiels, Spent fuel transportation applications assessment of cladding performance, Tech. rep., Electric Power Research Institute (2007).

[90] Z. Pan, I. Ritchie, M. Puls, The terminal solid solubility of hydrogen and deuterium in Zr-2.5Nb alloys, Journal of Nuclear Materials 228 (2) (1996) pp. 227-237.

[91] M. Puls, The Effect of Hydrogen and Hydrides on the Integrity of Zirconium Alloy Components, Springer, 2012.

[92] R. Tang, X. Yang, Dissolution and precipitation behaviors of hydrides in N18, Zry-4 and M5 alloys, International Journal of Hydrogen Energy 34 (17) (2009) pp. 7269-7274.

[93] A. McMinn, E. Darby, J. Schofield, The terminal solid solubility of hydrogen in zirconium alloys, in: G. Sabol, G. Moan (Eds.), 12th International Symposium on Zirconium in the Nuclear Industry, ASTM STP 1354, Toronto, Canada, (2000), pp. 173-195.

[94] P. Vizcaino, A. Banchik, J. Abriata, Solubility of hydrogen in Zircaloy4: irradiation induced increase and thermal recovery, Journal of Nuclear Materials 304 (2002) pp. 96-106.

[95] P. Vizcaino, A. Banchik, J. Abriata, Hydride phase dissolution enthalpy in neutron irradiated Zircaloy-4, Journal of Nuclear Materials 336 (1) (2005) pp. 54-64.

[96] A. Sasahara, T. Matsumura, Post-irradiation examinations focused on fuel integrity of spent BWR-MOX and PWR-UO2 fuels stored for 20 years, Nuclear Engineering and Design 238 (5) (2008) pp. 1250-1259.

[97] M. Iwasawa, T. Ohnuma, N. Soneda, Ab initio electronic structure study of alpha - zirconium and hydrogen, Materials Transactions 49 (12) (2008) pp. $2765-2769$.

[98] M. Lewis, Deuterium-defect trapping in ion-irradiated zirconium, Journal of Nuclear Materials 125 (2) (1984) pp. 152-159. 
[99] K. Une, S. Ishimoto, Y. Etoh, K. Ito, K. Ogata, T. Baba, K. Kamimura, Y. Kobayashi, The terminal solid solubility of hydrogen in irradiated Zircaloy-2 and microscopic modeling of hydride behavior, Journal of Nuclear Materials 389 (1) (2009) pp. 127-136.

[100] F. Garzarolli, R. Manzel, A. Seibold, Corrosion phenomena at high burnup, in: 10th International Conference on Environmental Degradation of Materials in Nuclear Power Systems, Lake Tahoe, Nevada, (2001).

[101] IAEA, Thermophysical properties database of materials for light water reactors and heavy water reactors, Tech. Rep. TECDOC-1496, IAEA (2006). 